\section{OAK RIDGE \\ NATIONAL LABORATORY}

MANAGED BY UT-BATTELLE

FOR THE DEPARTMENT OF ENERGY

\title{
Calculation Analysis of San Onofre Depletion MOX Fuel Experiment
}

Project Manager

A. M. Pavlovichev

A. Belov

V. I. Bryzgalov

A. Kalashnikov

E. Kapranova

A. Tsyboulia

M. S. Yudkevich

A Russian Contribution to the Fissile Materials Disposition Program

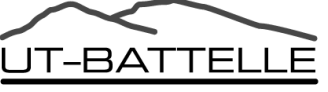




\section{DOCUMENT AVAILABILITY}

Reports produced after January 1, 1996, are generally available free via the U.S. Department of Energy (DOE) Information Bridge.

Web site http://www.osti.gov/bridge

Reports produced before January 1, 1996, may be purchased by members of the public from the following source.

National Technical Information Service

5285 Port Royal Road

Springfield, VA 22161

Telephone 703-605-6000 (1-800-553-6847)

TDD 703-487-4639

Fax 703-605-6900

E-mail info@ntis.fedworld.gov

Web site http://www.ntis.gov/support/ordernowabout.htm

Reports are available to DOE employees, DOE contractors, Energy Technology Data Exchange (ETDE) representatives, and International Nuclear Information System (INIS) representatives from the following source.

Office of Scientific and Technical Information

P.O. Box 62

Oak Ridge, TN 37831

Telephone 865-576-8401

Fax 865-576-5728

E-mail reports@adonis.osti.gov

Web site http://www.osti.gov/contact.html

This report was prepared as an account of work sponsored by an agency of the United States Government. Neither the United States Government nor any agency thereof, nor any of their employees, makes any warranty, express or implied, or assumes any legal liability or responsibility for the accuracy, completeness, or usefulness of any information, apparatus, product, or process disclosed, or represents that its use would not infringe privately owned rights. Reference herein to any specific commercial product, process, or service by trade name, trademark, manufacturer, or otherwise, does not necessarily constitute or imply its endorsement, recommendation, or favoring by the United States Government or any agency thereof. The views and opinions of authors expressed herein do not necessarily state or reflect those of the United States Government or any agency thereof. 


\title{
CALCULATION ANALYSIS OF SAN ONOFRE DEPLETION MOX FUEL EXPERIMENT
}

Project Manager

A. M. Pavlovichev

A. Belov

V. I. Bryzgalov

A. Kalashnikov

E. Kapranova

A. Tsyboulia

M. S. Yudkevich

Date Published: August 2001

\author{
Prepared by \\ Russian Research Center "Kurchatov Institute" \\ Institute of Nuclear Reactors \\ under subcontract 85B-99398V \\ Funded by \\ Office of Fissile Materials Disposition \\ U.S. Department of Energy \\ Prepared for \\ Computational Physics and Engineering Division \\ OAK RIDGE NATIONAL LABORATORY \\ Oak Ridge, Tennessee 37831 \\ managed by \\ UT-BATTELLE, LLC \\ for the \\ U.S. DEPARTMENT OF ENERGY \\ under contract DE-AC05-00OR22725
}




\title{
Russian Research Center "Kurchatov Institute" Institute of Nuclear Reactors VVER Division
}

State Scientific Centre of the Russian Federation Leipunski Institute for Physics and Power Engineering

Joint U.S. / Russian Project to Update, Verify and Validate Reactor Design/Safety Computer Codes Associated with Weapons-Grade Plutonium Disposition in WVER Reactors

\author{
Calculation Analysis \\ of San Onofre Depletion MOX Fuel Experiment
}

General Order 85B-99398V

(Report)

Project Manager

A.M.Pavlovichev

Moscow 2000 


\section{FOREWORD}

The report issued according to Work Release 02. P. 99-7c presents calculation results of isotopic composition of spent MOX fuel irradiated in San Onofre PWR.

The Report consists of two independent parts:

Part 1 fulfilled in RRC Kurchatov Institute. It contains the results of calculations by MCU/BURNUP Monte Carlo code.

Part 2 fulfilled in SSC RF IPPE. The results presented here were obtained by CONKEMO Code. 


\section{Part 1}

\section{Calculation Analysis of San Onofre Depletion MOX Fuel Experiment}

Executed by

V. I. Bryzgalov

M. S. Yudkevich 


\section{CONTENTS}

$\begin{array}{ll}\text { Page } & \text { Pan }\end{array}$

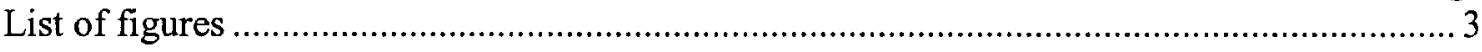

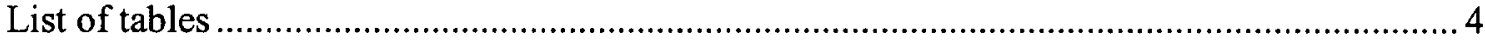

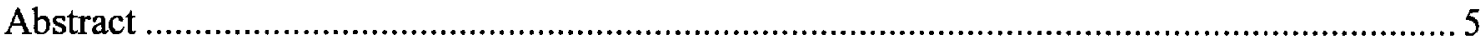

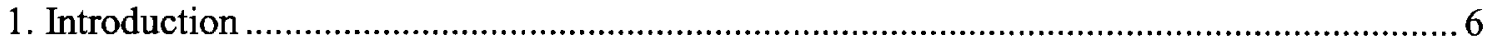

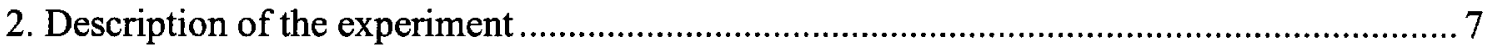

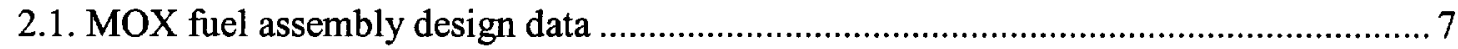

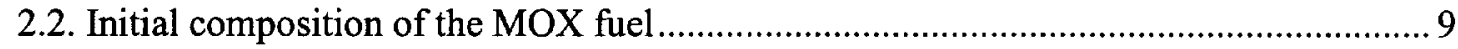

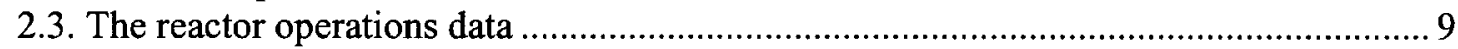

2.4. The result of isotopic measurement for irradiated samples.................................... 10

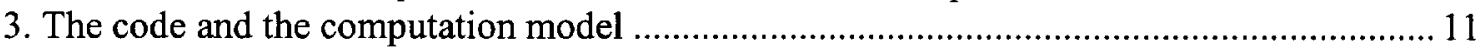

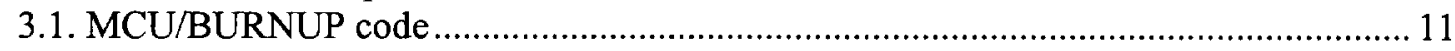

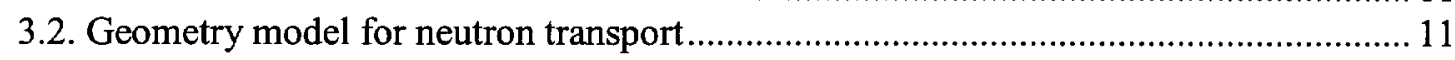

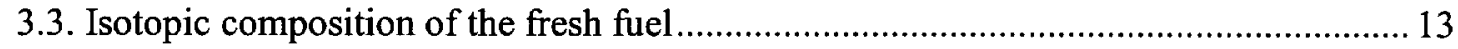

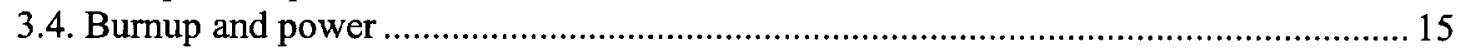

4. Calculation of isotopic composition of depleted MOX fuel and comparison with the

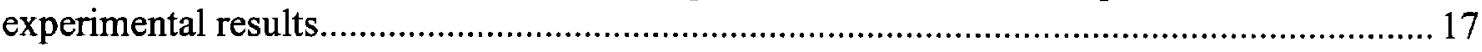

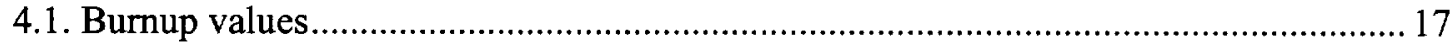

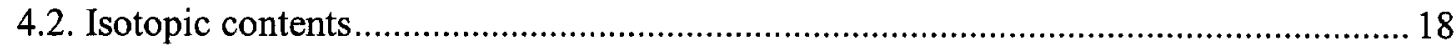

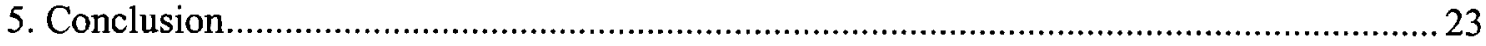

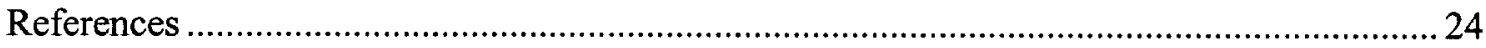

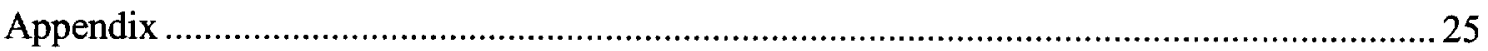




\section{LIST OF FIGURES}

\section{Figure}

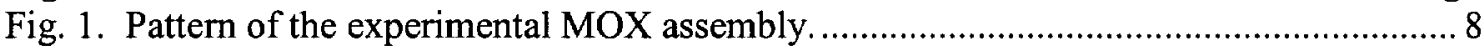

Fig. 2. Generation and decay of heavy metal isotopes.......................................................... 12

Fig. 3. ${ }^{238} \mathrm{Pu}$ content in mixture of plutonium isotopes depending on burnup. ....................... 14

Fig. 4. ${ }^{236} \mathrm{Pu}$ content in mixture of plutonium isotopes depending on burnup. ....................... 14

Fig. 5. Burnup determination from ${ }^{148} \mathrm{Nd}$ to ${ }^{238} \mathrm{U}$ atom density ratio.................................. 17 


\section{LIST OF TABLES}

Table

Table 1. Main parameters of the MOX fuel assemblies............................................................ 7

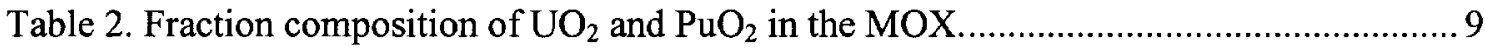

Table 3. Content of the isotopes in uranium and plutonium................................................

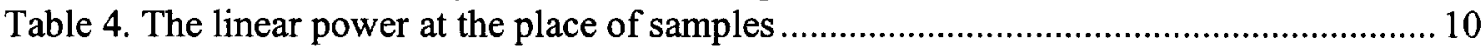

Table 5. The measured isotopic composition of the pellets in atom ratios ............................ 10

Table 6. Weight content of isotopes of fuel in time of analysis before irradiation.................. 15

Table 7. Time-depended power of the assembly and the pins. .......................................... 16

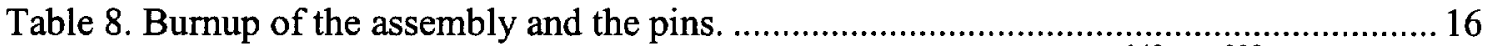

Table 9. Burnup of the assembly and the pins obtained from measured ${ }^{148} \mathrm{Nd} /{ }^{238} \mathrm{U}$........... 17

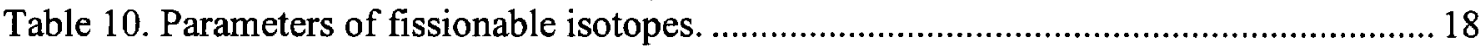

Table 11. Atom ratios calculation results and percentage difference with measured results... 19

Table 12. Measured isotopic content of spent fuel, $\quad$ gram per kilogram of initial

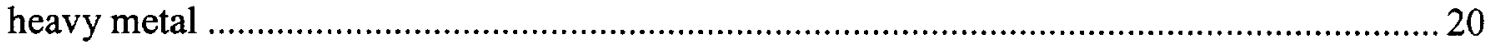

Table 13. Predicted isotopic content of spent fuel, gram per kilogram of initial heavy metal and percentage difference with measured results.

Table 14. Percentage difference of spent fuel isotopic content calculated results by MCU/BURNUP and SCALE (SAS2H) codes with measured results 


\section{ABSTRACT}

The report provides calculation results of isotopic composition of spent MOX fuel irradiated in Sun Onofre PWR reactor. The calculation was performed by means of the MCU/BURNUP Monte Carlo code. The code is developed in Kurchatov Institute, Russia.

The predicted isotope contents are compared with the measured ones.

A purpose of this work is a verification both the code and the model of experiment description.

Predicted plutonium content exceeds the measured one approximately by $3 \%$. It is arise mainly from error of ${ }^{239} \mathrm{Pu}$ isotope. Isotopic contents of the main plutonium and uranium isotopes are predicted with satisfactory precision. 


\section{INTRODUCTION}

Since 1996 the Joint U.S./Russian Project to Verify and Validate Reactor Design/Safety Computer Codes Associated with MOX Fuel Usage in Water Reactors has been carried out within the framework of Fissile Material Disposition Program. The MCU Monte Carlo code [1] is used as a reference code in Kurchatov Institute.

Most part of the work with MCU code was concerned with critical experiment with fresh uranium and MOX fuel. Only one experiment with spent MOX fuel irradiated in QuadCities-1 reactor was analyzed [2]. Five $\mathrm{UO}_{2}$ and four MOX pellet samples were investigated. All samples have close values of burnup, no more then $14 \mathrm{MWd} / \mathrm{kgHM}$.

In the current work an experiment at San Onofre PWR reactor is considered. The experiment is described in report [3]. Atom density ratios of six depleted MOX pellet samples were measured. Sample's burnup values were approximately from 7 to $21 \mathrm{MWd} / \mathrm{kgHM}$.

The three moments define a precision of isotope contents of a spent fuel. These are: neutron data used, algorithm of neutron spectrum calculation, correspondence of calculation model and real design. MCU/BURNUP version of MCU was used for computer modeling of San Onofre experiment. Neutron database of this code has been verified earlier and does not rise any doubt applied to fuel depletion problem. Monte Carlo method is used for modeling neutron spectrum without any simplification of geometry. Thus, a testing of the calculation model is a main goal of the work fulfilled. It is an important subject as similar model is often in use in reactor design codes, in particular TVS-M code [4] of Russian reactor VVER type.

San Onofre experiment was analyzed also by the SCALE (SAS2H) code [5]. Comparison of MCU/BURNUP and SCALE (SAS2H) codes is provided in Appendix. 


\section{DESCRIPTION OF THE EXPERIMENT}

This chapter is a summary of ref. [3], issues 2,3 and 4 .

The experimental MOX fuel assemblies were located at the start of cycle 2 in a core of PWR type reactor of the San Onofre Nuclear Generation Station, Unit 1.

One assembly was irradiated during cycle 2 . This assembly was placed in immediate proximity of the reflector. The second assembly was placed at the third row from reflector and was irradiated during both cycles 2 and 3 .

\subsection{MOX FUEL ASSEMBLY DESIGN DATA}

The assembly contains 180 fuel rods, 15 guide tubes and 1 instrument tube. The patterns for assembly are presented at Fig. 1. Parameters, which are necessary for prediction of depletion fuel, are listed in Table 1.

Design of ordinary $\mathrm{UO}_{2}$ assemblies is not presented in ref. [3].

Table 1. Main parameters of the MOX fuel assemblies

\begin{tabular}{|l|l|}
\hline \multicolumn{1}{|c|}{ Parameter } & \multicolumn{1}{|c|}{ Data } \\
\hline General data & \\
\hline Assembly pitch & $19.941 \mathrm{~cm}$ \\
Rod lattice & $14 \times 14$ \\
Rod pitch & $1.41224 \mathrm{~cm}$ \\
Average moderator (water) temperature & $576.5 \mathrm{~K}$ \\
Average moderator density & $0.7179 \mathrm{~g} / \mathrm{cm}^{3}$ \\
Soluble boron, wt & $500 \mathrm{ppm}$ \\
& \\
Fuel rod data & \\
\hline Fuel pellet & UO $\mathrm{plus} \mathrm{PuO}_{2}$ (MOX) \\
Pellet diameter & $0.92939 \mathrm{~cm}$ \\
Stack density & $10.2235 \mathrm{~g} / \mathrm{cm}^{3}$ \\
Fuel temperatures cycle 2, cycle 3: & $\mathrm{K}$ \\
Pin ID (height, in.): & \\
067 (53.0) & 744 \\
141 (95.5) & 713 \\
079 (49.0) & 718839 \\
$167(16.5)$ & 695787 \\
167 (16.5) & 705805 \\
167 (16.5) & 650703 \\
Clad material & Zircaloy-4 \\
Clad OD & $1.07188 \mathrm{~cm}$ \\
Clad ID & $0.94844 \mathrm{~cm}$ \\
Clad temperature & $615 \mathrm{~K}$ \\
Guide tubes & \\
\hline Material & Stainless steel -304 \\
Tube OD & $1.35890 \mathrm{~cm}$ \\
Tube ID & $1.29794 \mathrm{~cm}$ \\
\hline
\end{tabular}




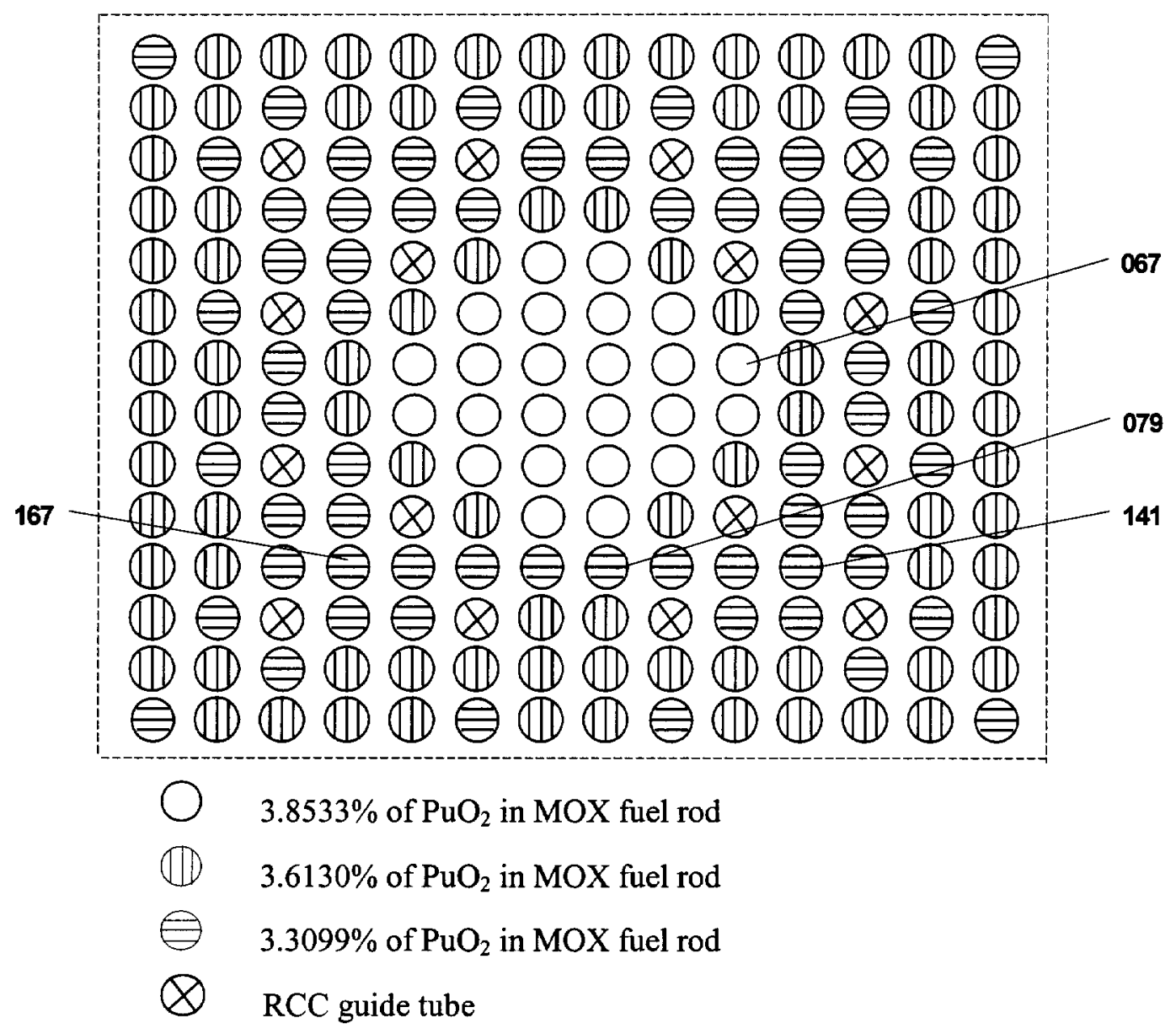

Fig. 1. Pattern of the experimental MOX assembly. 


\subsection{INITIAL COMPOSITION OF THE MOX FUEL}

Fraction compositions of $\mathrm{UO}_{2}$ and $\mathrm{PuO}_{2}$ in the MOX fuel are given in Table 2.

Compositions of uranium and plutonium are presented in Table 3. Isotopic analysis has been made 605 days before the start of irradiation.

Table 2. Fraction composition of $\mathrm{UO}_{2}$ and $\mathrm{PuO}_{2}$ in the MOX.

\begin{tabular}{|c|c|c|c|}
\hline \multirow{2}{*}{ Pin ID } & Fissile Pu & \multicolumn{2}{|c|}{ Weight fraction } \\
\cline { 3 - 4 } & Wt \% & $\mathbf{U O}_{\mathbf{2}}$ & PuO $_{\mathbf{2}}$ \\
\hline 067 & 3.31 & 0.961423 & 0.038577 \\
141 & 2.84 & 0.966901 & 0.033099 \\
079 & 3.10 & 0.963870 & 0.036130 \\
167 & 2.84 & 0.966901 & 0.033099 \\
\hline
\end{tabular}

Table 3. Content of the isotopes in uranium and plutonium.

\begin{tabular}{|c|c|}
\hline Isotope & Content \\
\hline Uranium & Atom \% in U \\
$234 \mathrm{U}$ & 0.0055 \\
$235 \mathrm{U}$ & 0.7200 \\
$238 \mathrm{U}$ & 99.2745 \\
\hline Plutonium & Atom \% in Pu \\
$239 \mathrm{PU}$ & 80.6 \\
$240 \mathrm{PU}$ & 13.4 \\
$241 \mathrm{PU}$ & 5.2 \\
$241 \mathrm{PU}$ & 0.8 \\
\hline Americium & ppm of Pu \\
$241 \mathrm{Am}$ & 5000 \\
\hline
\end{tabular}

\subsection{THE REACTOR OPERATIONS DATA}

The duration of cycles 2 and 3 equals 403 and 459 days respectfully. The time distance between cycles is equal to 66 days.

During a cycle the reactor operates at constant power.

The linear power in both cycles at the place of samples' location is given in Table 4. 
Part 1. Calculation Analysis

of San Onofre Depletion MOX Fuel Experiment

Table 4. The linear power at the place of samples

\begin{tabular}{|c|c|c|}
\hline \multirow{2}{*}{$\begin{array}{c}\text { Pin ID } \\
\text { (height, in) }\end{array}$} & \multicolumn{2}{|c|}{ Linear power, kw/ft } \\
\cline { 2 - 3 } & Cycle 2 & Cycle 3 \\
\hline $079(49.0)$ & 3.8 & 6.6 \\
$167(16.5)$ & 3.7 & 6.2 \\
$167(95.5)$ & 3.7 & 6.2 \\
$167(114.0)$ & 2.0 & 2.0 \\
\hline
\end{tabular}

\subsection{THE RESULT OF ISOTOPIC MEASUREMENT FOR IRRADIATED SAMPLES}

The measured isotopic composition, in atom ratios, of the six sample pellets are presented in Table 5. The time distance between end of irradiation and isotopic analysis is also indicated.

The first 11 isotopic ratios (through ${ }^{148} \mathrm{Nd} /{ }^{238} \mathrm{U}$ ) that are listed in Table 5 were performed by mass spectrometric methods. The remaining five ratios in the Table 5 were measured by alpha spectrometry.

Standard deviation or uncertainties for the experimental data is not provided in ref. [3].

Table 5. The measured isotopic composition of the pellets in atom ratios

\begin{tabular}{|c|c|c|c|c|c|c|}
\hline $\begin{array}{l}\text { Pin ID } \\
\text { (height, in) }\end{array}$ & $\begin{array}{c}067 \\
(53.0) \\
\end{array}$ & $\begin{array}{c}141 \\
(95.5)\end{array}$ & $\begin{array}{c}079 \\
(49.0) \\
\end{array}$ & $\begin{array}{c}167 \\
(16.5) \\
\end{array}$ & $\begin{array}{c}167 \\
(95.5) \\
\end{array}$ & $\begin{array}{c}167 \\
(114.0) \\
\end{array}$ \\
\hline Days after shutdown & 717 & 719 & 194 & 187 & 187 & 192 \\
\hline${ }^{234} \mathrm{U} / \mathrm{U} \times 10^{2}$ & 0.005 & 0.006 & 0.005 & 0.005 & 0.005 & 0.005 \\
\hline${ }^{235} \mathrm{U} / \mathrm{U} \times 10^{2}$ & 0.628 & 0.641 & 0.470 & 0.483 & 0.479 & 0.569 \\
\hline${ }^{236} \mathrm{U} / \mathrm{U} \times 10^{2}$ & 0.023 & 0.018 & 0.052 & 0.050 & 0.051 & 0.032 \\
\hline${ }^{238} \mathrm{U} / \mathrm{U} \times 10^{2}$ & 99.344 & 99.335 & 99.473 & 99.462 & 99.465 & 99.394 \\
\hline${ }^{236} \mathrm{Pu} / \mathrm{Pu} \times 10^{2}$ & 0.557 & 0.462 & 0.989 & 0.860 & 0.884 & 0.642 \\
\hline${ }^{238} \mathrm{Pu} / \mathrm{Pu} \times 10^{2}$ & 71.886 & 73.218 & 56.998 & 57.626 & 57.130 & 66.193 \\
\hline${ }^{239} \mathrm{Pu} / \mathrm{Pu} \times 10^{2}$ & 19.050 & 18.812 & 26.422 & 26.613 & 26.593 & 22.401 \\
\hline${ }^{240} \mathrm{Pu} / \mathrm{Pu} \times 10^{2}$ & 7.210 & 6.384 & 12.530 & 12.047 & 12.444 & 9.088 \\
\hline${ }^{241} \mathrm{Pu} / \mathrm{Pu} \times 10^{2}$ & 1.295 & 1.124 & 3.061 & 2.854 & 2.949 & 1.678 \\
\hline${ }^{242} \mathrm{Pu} / \mathrm{Pu} \times 10^{2}$ & 2.619 & 2.293 & 1.741 & 1.594 & 1.601 & 1.965 \\
\hline${ }^{146} \mathrm{Nd} /{ }^{238} \mathrm{U} \times 10^{4}$ & 1.508 & 1.250 & 3.975 & 3.226 & 3.460 & 2.046 \\
\hline${ }^{241} \mathrm{Am} /{ }^{239} \mathrm{Pu} \times 10^{2}$ & $-^{a}$ & - $^{\mathbf{a}}$ & $-^{a}$ & 6.51 & 6.83 & 1.59 \\
\hline${ }^{243} \mathrm{Am} /{ }^{239} \mathrm{Pu} \times 10^{2}$ & $-^{\mathrm{a}}$ & $\ldots^{a}$ & $-^{a}$ & 1.41 & 1.55 & 0.27 \\
\hline${ }^{236} \mathrm{Pu} /{ }^{239} \mathrm{Pu} \times 10^{9}$ & 4.04 & 4.60 & 17.7 & 12.4 & 13.4 & 6.50 \\
\hline${ }^{238} \mathrm{Pu} /{ }^{239} \mathrm{Pu} \times 10^{9}$ & 7.65 & 6.16 & 17.0 & 14.7 & 15.2 & 9.43 \\
\hline${ }^{237} \mathrm{~Np} / \mathrm{U} \times 10^{5}$ & $-^{a}$ & $-^{a}$ & $-^{a}$ & 9.7 & 11.1 & 5.7 \\
\hline
\end{tabular}

${ }^{\mathrm{a}}$ No measurement.

${ }^{b}$ In place of atom ratio, units are grams ${ }^{237} \mathrm{~Np} / \mathrm{g} \mathrm{U}$ 


\section{THE CODE AND THE COMPUTATION MODEL}

\subsection{MCU/BURNUP CODE}

The MCU/BURNUP code was used in current work to calculate the change of the fuel isotopic composition during the reactor operation. The code consists of two modules working in cycles: MCU [6] and BURNUP [7]. Each module constitutes an independent code.

The MCU code calculates the space and energy dependent neutron spectrum by Monte Carlo method. Continuous energy approach is used for modeling of neutron histories. One of the results of its work is the neutron spectrum averaged cross sections of the isotopes of each burnable material and the power distribution by materials.

The BURNUP code calculates a change of the isotopic composition of the burnable materials with given initial composition, cross sections of isotopes and power. Analytical method is used for solving equation that describes time depended isotope densities. Scheme of depletion and generation of isotopes investigated in current work is presented at Fig. 2. Main paths are marked out by reach lines.

The calculation of whole campaign is carried out by means of successive time steps.

An iteration method of prediction with subsequent correction is used to take into account materials' isotopes cross sections and power production dependence on the time of reactor operation. This method allows one to increase time step significantly, in comparison to the traditional method. It is especially important when a Monte Carlo code is used.

Earlier, MCU/BURNUP code has been successfully tested on international benchmarks of closed water moderated cell with LEU and MOX fuel.

\subsection{GEOMETRY MODEL FOR NEUTRON TRANSPORT}

The unit for Monte Carlo modeling of neutron transport is rectangular parallelepiped with white reflector condition at the side borders. In XY plane cross section of parallelepiped is a square with side equals assembly pitch $19.941 \mathrm{~cm}$. A square $14 \times 14$ lattice - consisted of the fuel rods and instrumentation tubes - is placed inside. The geometry and contents of each rod and tube is absolutely identical to that of real design as it is described in ref. [3] (see Table 1 and Fig. 1). All the elements of the model assembly are taken as homogenous and infinite by $Z$ axis.

Two ideas are implemented in the computation model. Firstly, exact coincidence of the model and the real design inside of an assembly. Secondly, a complete negligence of a assembly environment on the neutron spectrum.

This model is often in use in reactor design codes, in particular TVS-M code [5] of Russian reactor VVER type. 

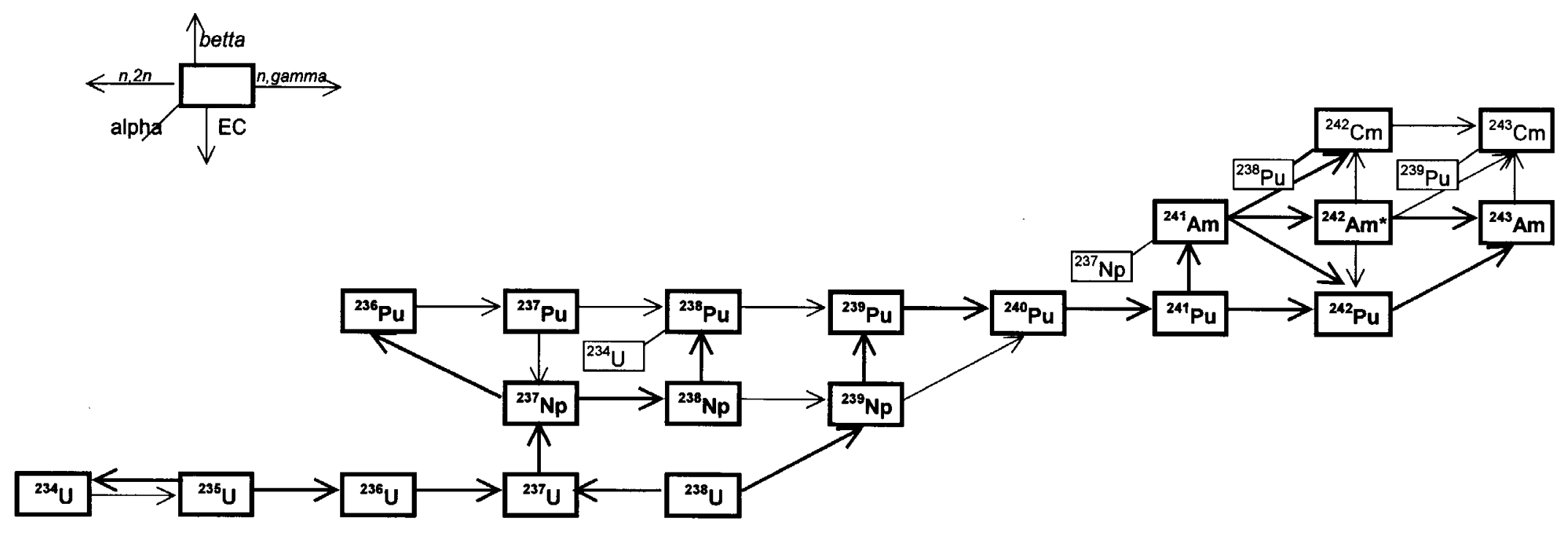

Fig. 2. Generation and decay of heavy metal isotopes. 


\subsection{ISOTOPIC COMPOSITION OF THE FRESH FUEL}

Data presented in ref. [3] (Tables 2 and 3 of Chapter 1) allow one to obtained contents of plutonium isotopes from ${ }^{239} \mathrm{Pu}$ through ${ }^{242} \mathrm{Pu}$. However it is clear that plutonium must contain also ${ }^{236} \mathrm{Pu}$ and ${ }^{238} \mathrm{Pu}$ isotopes. One can estimate their quantities on the basis of measured burnup-content dependence density.

To estimate ${ }^{238} \mathrm{Pu}$ content the samples with the same MOX initial parameters should be considered, namely pellets of 141 and 167 pins. The measured ${ }^{238} \mathrm{Pu} / \mathrm{Pu}$ and ${ }^{238} \mathrm{Pu} /{ }^{239} \mathrm{Pu}$ values depending on ${ }^{146} \mathrm{Nd} /{ }^{238} \mathrm{U}$ (Table 5) are given at the diagram of Fig. 3. Extrapolation of the both curves to zero ${ }^{146} \mathrm{Nd} /{ }^{238} \mathrm{U}$ ratio (zero burnup) gives close values. ${ }^{238} \mathrm{Pu} / \mathrm{Pu}=0.0032$ is accepted for the following calculations.

${ }^{236} \mathrm{Pu}$ half-life equal 2.86 years. That is comparable to irradiation period. Therefore, only samples that were equally irradiated may be examined. On the other hand, ${ }^{236} \mathrm{Pu}$ is generated only from uranium isotopes (see Fig. 2) and pellets with any MOX composition may be considered simultaneously. So pellets of 079 and 167 pins were examined.

The measured ${ }^{236} \mathrm{Pu} / \mathrm{Pu}(\mathrm{T}=0)$ dependence on ${ }^{146} \mathrm{Nd} /{ }^{238} \mathrm{U}$ is given at the diagram of Fig. 4. $\mathrm{Pu}(\mathrm{T}=0)$ is plutonium density in fresh fuel. Extrapolation of the curve to zero burnup gives ${ }^{236} \mathrm{Pu} / \mathrm{Pu}(\mathrm{T}=0)$ ratio equal $3 \times 10^{-9}$. The same ratio adjusted to the time of analysis of MOX content is equal to approximately $9 \times 10^{-9}$.

The values obtained could only be considered as a reference point because the form of trend lines has been chosen arbitrary. Nevertheless, they are useful to estimate a value of effect.

Content of uranium isotopes in the description ref. [3] corresponds to native uranium. However in MOX, ${ }^{234} \mathrm{U}$ content is slightly higher than normal. Additional source is alpha decay of ${ }^{238} \mathrm{Pu}$ (half-life $\mathrm{T}_{1 / 2}=87.74$ years). The value of additional ${ }^{234} \mathrm{U}$ could be estimated in the following way:

$$
\frac{{ }^{234} \mathrm{U}}{{ }^{238} \mathrm{Pu}}=\frac{{ }^{241} \mathrm{Am}}{{ }^{241} \mathrm{Pu}} * \frac{\mathrm{T}_{1 / 2}^{241} \mathrm{Am}}{\mathrm{T}_{1 / 2}^{238} \mathrm{Pu}}
$$

Alpha decay of ${ }^{241} \mathrm{Am}$ (half-life $\mathrm{T}_{1 / 2}=432.2$ year) generates ${ }^{237} \mathrm{~Np}$ (see Fig. 2). The value of ${ }^{237} \mathrm{~Np}$ could be estimated in the similar way:

$$
\frac{{ }^{237} \mathrm{~Np}}{{ }^{241} \mathrm{Am}}=0.5^{241} \frac{{ }^{241}}{{ }^{241} \mathrm{Pu}} * \frac{\mathrm{T}_{1 / 2}^{241} \mathrm{Pu}}{\mathrm{T}_{1 / 2}^{241} \mathrm{Am}}
$$

Calculation of the depleted fuel isotopic content has been carried out with two sets of initial compositions. One set corresponds to ref. [3] recommendation. Second set (revised) takes into account additional isotopes. Weight contents of isotopes in heavy metal at the time of analysis of fuel before irradiation are listed in Table 6 for both cases. 
Part 1. Calculation Analysis

of San Onofre Depletion MOX Fuel Experiment

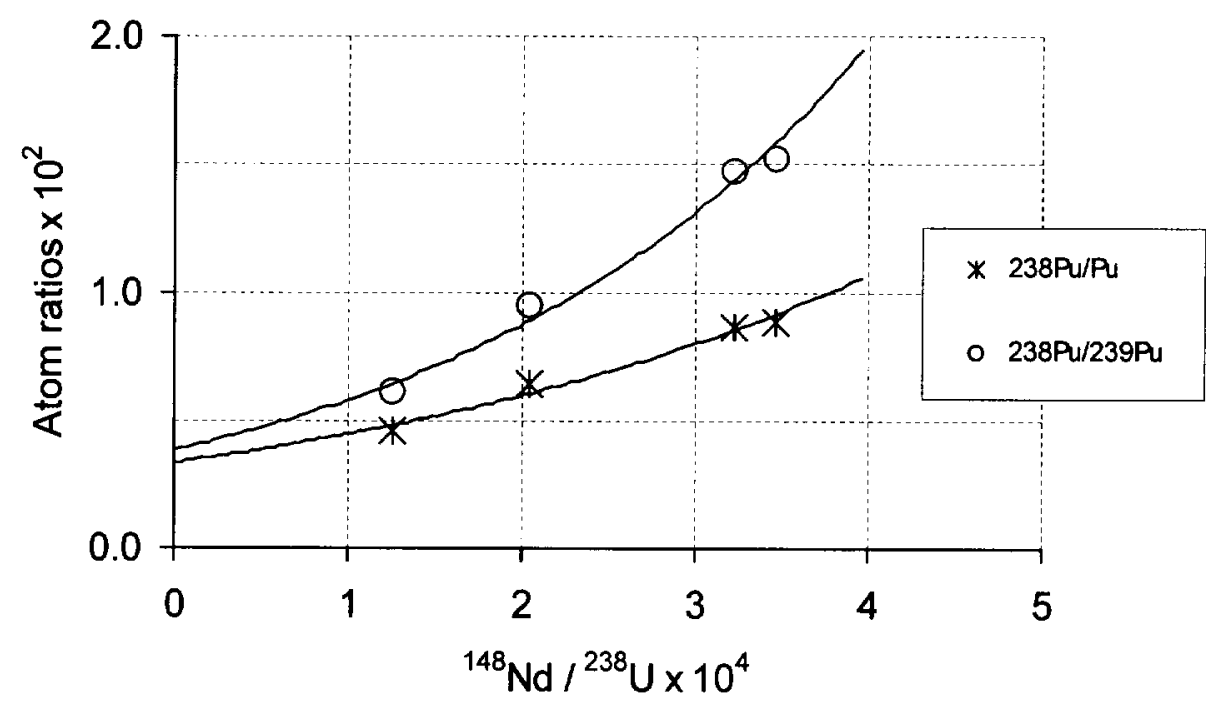

Fig. 3. ${ }^{238} \mathrm{Pu}$ content in mixture of plutonium isotopes depending on burnup.

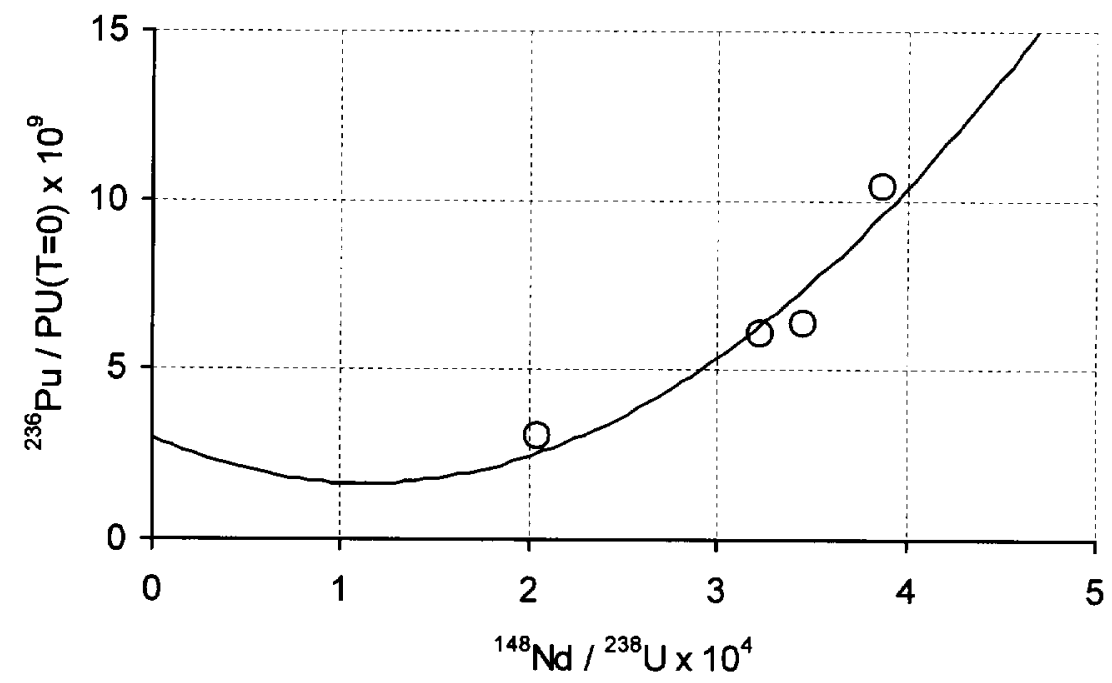

Fig. 4. ${ }^{236} \mathrm{Pu}$ content in mixture of plutonium isotopes depending on burnup. 
Part 1. Calculation Analysis

of San Onofre Depletion MOX Fuel Experiment

Table 6. Weight content of isotopes of fuel in time of analysis before irradiation.

\begin{tabular}{|c|c|c|c|}
\hline \multirow{3}{*}{ Isotope } & \multicolumn{3}{|c|}{ Isotopic content $W \mathrm{t}, \mathrm{g} / \mathrm{kgHM}$} \\
\hline & \multicolumn{3}{|c|}{ Pin ID } \\
\hline & 067 & 079 & 141,167 \\
\hline${ }^{234} U^{a}$ & 0.0520 & 0.0521 & 0.0523 \\
\hline${ }^{234} \mathbf{U}^{b}$ & 0.0539 & 0.0539 & 0.0555 \\
\hline${ }^{235} \mathbf{U}$ & 6.8338 & 6.8513 & 6.8730 \\
\hline${ }^{236} \mathrm{U}$ & 0.0 & 0.0 & 0.0 \\
\hline${ }^{238} \mathbf{U}$ & 95.433 & 95.677 & 95.979 \\
\hline${ }^{237} \mathbf{N p}{ }^{\text {a }}$ & 0.0 & 0.0 & 0.0 \\
\hline${ }^{237} \mathbf{N p}{ }^{b}$ & 0.00031 & 0.00029 & 0.00026 \\
\hline${ }^{236} \mathrm{Pu} \times 10^{7}$ & 0.0 & 0.0 & 0.0 \\
\hline${ }^{236} \mathrm{Pu} \times 10^{7}$ & 3.59 & 3.36 & 3.08 \\
\hline${ }^{238} \mathrm{Pu}{ }^{\mathrm{a}}$ & 0.0 & 0.0 & 0.0 \\
\hline${ }^{238} \mathrm{Pu}{ }^{b}$ & 0.123 & 0.115 & 0.105 \\
\hline${ }^{239} \mathrm{Pu}$ & 31.072 & 29.101 & 26.660 \\
\hline${ }^{240} \mathrm{Pu}$ & 5.187 & 4.858 & 4.451 \\
\hline${ }^{241} \mathbf{P u}$ & 2.021 & 1.893 & 1.734 \\
\hline${ }^{242} \mathbf{P u}$ & 0.312 & 0.293 & 0.268 \\
\hline${ }^{241} \mathrm{Am}$ & 0.194 & 0.182 & 0.167 \\
\hline${ }^{243} \mathrm{Am}$ & 0.0 & 0.0 & 0.0 \\
\hline
\end{tabular}

\subsection{BURNUP AND POWER}

Input data of MCU/BURNUP code are initial nuclear density and time-dependent average power of assembly at the pellet sample position.

In the current work power in each time cycle has been calculated from summary burnup and from relation of cycle 2 power and cycle 3 power (Table 4). Summary burnup was derived from the ${ }^{148} \mathrm{Nd} /{ }^{238} \mathrm{U}$ measurement. The procedure used is described in the issue 4.1.

Time of fresh fuel analysis is taken as starting time and time of depleted fuel analysis is taken as a final one. Power and burnup in the different periods of sample pellets irradiation are listed in Table 7 and Table 8 respectfully. These data differ slightly from ones recommended in ref. [3].

Note that only the power of assembly is used by MCU/BURNUP code as input data. Remaining data are presented for comparison with ref. [3] and other codes results. 
Table 7. Time-depended power of the assembly and the pins.

\begin{tabular}{|c|c|c|c|c|c|c|c|}
\hline & \multicolumn{6}{|c|}{ Pin ID (height, in) } \\
\hline & & $\begin{array}{c}067 \\
(53.0) \\
\end{array}$ & $\begin{array}{c}141 \\
(95.5)\end{array}$ & \begin{tabular}{|c|}
079 \\
$(49.0)$ \\
\end{tabular} & $\begin{array}{c}167 \\
(16.5) \\
\end{array}$ & $\begin{array}{c}167 \\
(95.5) \\
\end{array}$ & $\begin{array}{c}167 \\
(114.0) \\
\end{array}$ \\
\hline \multirow{2}{*}{$\begin{array}{l}\text { Before } \\
\text { irradiation }\end{array}$} & Days & 605 & 605 & 605 & 605 & 605 & 605 \\
\hline & $\mathrm{MW} / \mathrm{kgHM}$ & 0.0 & 0.0 & 0.0 & 0.0 & 0.0 & 0.0 \\
\hline \multirow[t]{4}{*}{ Cycle 2} & Days & 403 & 403 & 403 & 403 & 403 & 403 \\
\hline & $\mathrm{MW} / \mathrm{kgHM}$ & & & & & & \\
\hline & Assembly & 0.02103 & 0.01666 & 0.01730 & 0.01467 & 0.01568 & 0.00968 \\
\hline & Pin & 0.02044 & 0.01708 & 0.01736 & 0.01508 & 0.01594 & 0.00992 \\
\hline \multirow[t]{2}{*}{ Dead time } & Days & & & 66 & 66 & 66 & 66 \\
\hline & MW/kgHM & & & 0.0 & 0.0 & 0.0 & 0.0 \\
\hline \multirow[t]{4}{*}{ Cycle 3} & Days & & & 459 & 459 & 459 & 459 \\
\hline & $\mathrm{MW} / \mathrm{kgHM}$ & & & & & & \\
\hline & Assembly & & & 0.03020 & 0.0250 & 0.02630 & 0.01543 \\
\hline & Pin & & & 0.03036 & 0.02504 & 0.02696 & 0.01577 \\
\hline \multirow{2}{*}{$\begin{array}{l}\text { After } \\
\text { irradiation }\end{array}$} & Days & 717 & 719 & 194 & 187 & 187 & 192 \\
\hline & $\mathrm{MW} / \mathrm{kgHM}$ & 0.0 & 0.0 & 0.0 & 0.0 & 0.0 & 0.0 \\
\hline
\end{tabular}

Table 8. Burnup of the assembly and the pins.

\begin{tabular}{|c|c|c|c|c|c|c|c|}
\hline \multicolumn{2}{|c|}{} & \multicolumn{7}{|c|}{ Pin ID (height, in) } \\
\cline { 3 - 8 } \multicolumn{2}{|c|}{} & $\mathbf{0 6 7}$ & $\mathbf{1 4 1}$ & $\mathbf{0 7 9}$ & $\mathbf{1 6 7}$ & $\mathbf{1 6 7}$ & $\mathbf{1 6 7}$ \\
$\mathbf{( 5 3 . 0 )}$ & $\mathbf{( 9 5 . 5 )}$ & $\mathbf{( 4 9 . 0 )}$ & $\mathbf{( 1 6 . 5 )}$ & $\mathbf{( 9 5 . 5 )}$ & $\mathbf{( 1 1 4 . 0 )}$ \\
\hline Cycle 2 & Assembly & 8.475 & 6.691 & 6.971 & 5.910 & 6.317 & 3.900 \\
& Pin & 8.239 & 6.885 & 8.996 & 6.077 & 6.426 & 3.998 \\
\hline Cycle 3 & Assembly & - & - & 13.862 & 11.272 & 12.07 & 7.082 \\
& Pin & - & - & 13.937 & 11.493 & 12.373 & 7.239 \\
\hline Summa & Assembly & 8.475 & 6.691 & 20.833 & 17.182 & 18.387 & 10.962 \\
& Pin & 8.239 & 6.885 & 20.933 & 17.570 & 18.799 & 11.237 \\
\hline
\end{tabular}




\section{CALCULATION OF ISOTOPIC COMPOSITION OF DEPLETED MOX FUEL AND COMPARISON WITH THE EXPERIMENTAL RESULTS}

\subsection{BURNUP VALUES}

Measured values of ${ }^{148} \mathrm{Nd}$ to ${ }^{238} \mathrm{U}$ atom ratios may be directly linked to the burnup of the each sample pin and the whole assembly. To do that, the dependence of ${ }^{148} \mathrm{Nd} /{ }^{238} \mathrm{U}$ on burnup both for the assembly and the sample pins was calculated by the MCU/BURNUP code. Then the value of the burnup where the calculated ${ }^{148} \mathrm{Nd} /{ }^{238} \mathrm{U}$ value coincides with the measured one has been determined. This procedure is illustrated at the Fig. 5.

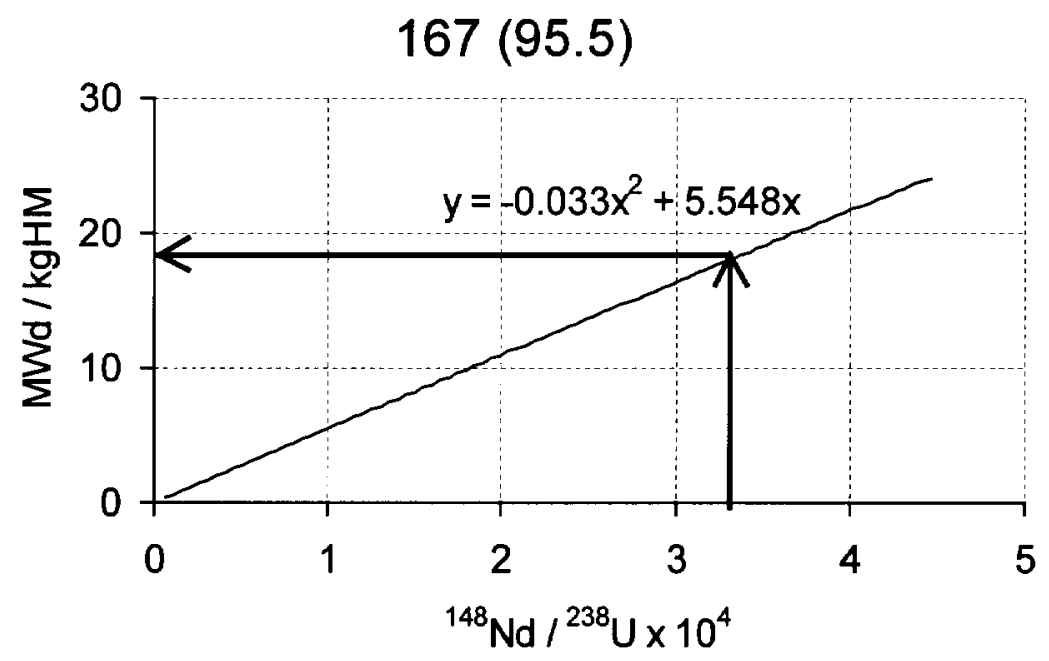

Fig. 5. Burnup determination from ${ }^{148} \mathrm{Nd}$ to ${ }^{238} \mathrm{U}$ atom density ratio.

Determined pin and assembly burnups are listed in Table 9. Data recommended in ref. [3] are presented too. Two sets are slightly different.

Table 9. Burnup of the assembly and the pins obtained from measured ${ }^{148} \mathrm{Nd} /{ }^{238} \mathrm{U}$.

\begin{tabular}{|c|c|c|c|}
\hline \multirow{2}{*}{$\begin{array}{c}\text { Pin ID } \\
\text { (height, in) }\end{array}$} & \multicolumn{3}{|c|}{ Burnup, MWd/kgHM } \\
\cline { 2 - 4 } & \multicolumn{2}{|c|}{ Current work } & Ref. [3] \\
\cline { 2 - 4 } & Assemble & Pin & Pin \\
\hline $\mathbf{0 6 7}(\mathbf{5 3 . 0})$ & 8.475 & 8.239 & 8.167 \\
$\mathbf{1 4 1}(\mathbf{9 5 . 5 )}$ & 6.691 & 6.885 & 6.808 \\
$\mathbf{0 7 9}(\mathbf{4 9 . 0 )}$ & 20.833 & 20.933 & 20.891 \\
$\mathbf{1 6 7}(\mathbf{1 6 . 5 )}$ & 17.182 & 17.570 & 17.447 \\
$\mathbf{1 6 7 ( 9 5 . 5 )}$ & 18.387 & 18.799 & 18.713 \\
$\mathbf{1 6 7}(\mathbf{1 1 4 . 0})$ & 10.962 & 11.237 & 11.065 \\
\hline
\end{tabular}


Burnup value is a key point for a prediction of a depleted fuel content. So the ${ }^{148} \mathrm{Nd}$ percent yield and energy per fission are listed in Table 10. These values are used by the MCU/BURNAP code. The relative contributions of the main fissionable isotopes to total fission number are given also. These values are the results of the MCU/BURNAP code calculation.

Table 10. Parameters of fissionable isotopes.

\begin{tabular}{|c|c|c|c|c|c|c|}
\hline \multicolumn{7}{|c|}{ Parameters of the fissionable isotopes } \\
\hline & & & ${ }^{235} \mathbf{U}$ & ${ }^{238} \mathbf{U}$ & ${ }^{239} \mathbf{P u}$ & ${ }^{241} \mathbf{P u}$ \\
\hline \multirow{2}{*}{\multicolumn{3}{|c|}{$\begin{array}{l}{ }^{148} \mathrm{Nd} \text { yield per fission, } \% \\
\text { Energy per fission, } \mathrm{MeV}\end{array}$}} & 1.673 & 2.094 & 1.642 & 1.932 \\
\hline & & & 201.7 & 202.8 & 210.6 & 211.3 \\
\hline \multicolumn{7}{|c|}{ The relative contribution to total fission number } \\
\hline & $067(53.0)$ & $141(95.5)$ & $079(49.0)$ & $167(16.5)$ & $167(95.5)$ & $167(114.0)$ \\
\hline${ }^{235} \mathbf{U}$ & 0.0904 & 0.1030 & 0.0944 & 0.1021 & 0.1015 & 0.1025 \\
\hline${ }^{238} \mathrm{U}$ & 0.0771 & 0.0720 & 0.0810 & 0.0772 & 0.0780 & 0.0744 \\
\hline${ }^{239} \mathbf{P u}$ & 0.7616 & 0.7581 & 0.7439 & 0.7429 & 0.7412 & 0.7516 \\
\hline${ }^{241} \mathrm{Pu}$ & 0.0709 & 0.0669 & 0.0807 & 0.0778 & 0.0793 & 0.0715 \\
\hline \multicolumn{7}{|c|}{ Averaged values of ${ }^{148} \mathrm{Nd}$ yield, $\%$ and averaged energy per fission, $\mathrm{MeV}$} \\
\hline & $067(53.0)$ & $141(95.5)$ & $079(49.0)$ & $167(16.5)$ & $167(95.5)$ & $167(114.0)$ \\
\hline$<{ }^{148} \mathbf{N d}>$ & 1.700 & 1.705 & 1.697 & 1.703 & 1.703 & 1.700 \\
\hline$<\mathbf{E}_{\mathrm{fis}}>$ & 209.2 & 209.2 & 209.2 & 209.1 & 209.1 & 209.1 \\
\hline
\end{tabular}

\subsection{ISOTOPIC CONTENTS}

In Table 11 the calculation results are presented in the same form as they are reported in ref. [3], namely in atom density relations. Percentage difference between calculated and measured values is also given.

The atom density relations obtained allow one to determine the content of involved isotopes in an irradiated fuel. To correlate the isotope content in spent fuel with a fresh fuel one should know the fuel disintegration. These values were calculated by the MCU/BURNUP code for each sample pellets.

Measured isotope contents of spent fuel are presented in Table 12. Amounts of heavy metal disintegrated during irradiation are indicated at the last line.

Calculated isotope contents are provided in Table 13 as well as a percentage difference between calculated and measured results. 
Part 1. Calculation Analysis

of San Onofre Depletion MOX Fuel Experiment

Table 11. Atom ratios calculation results and percentage difference with measured results.

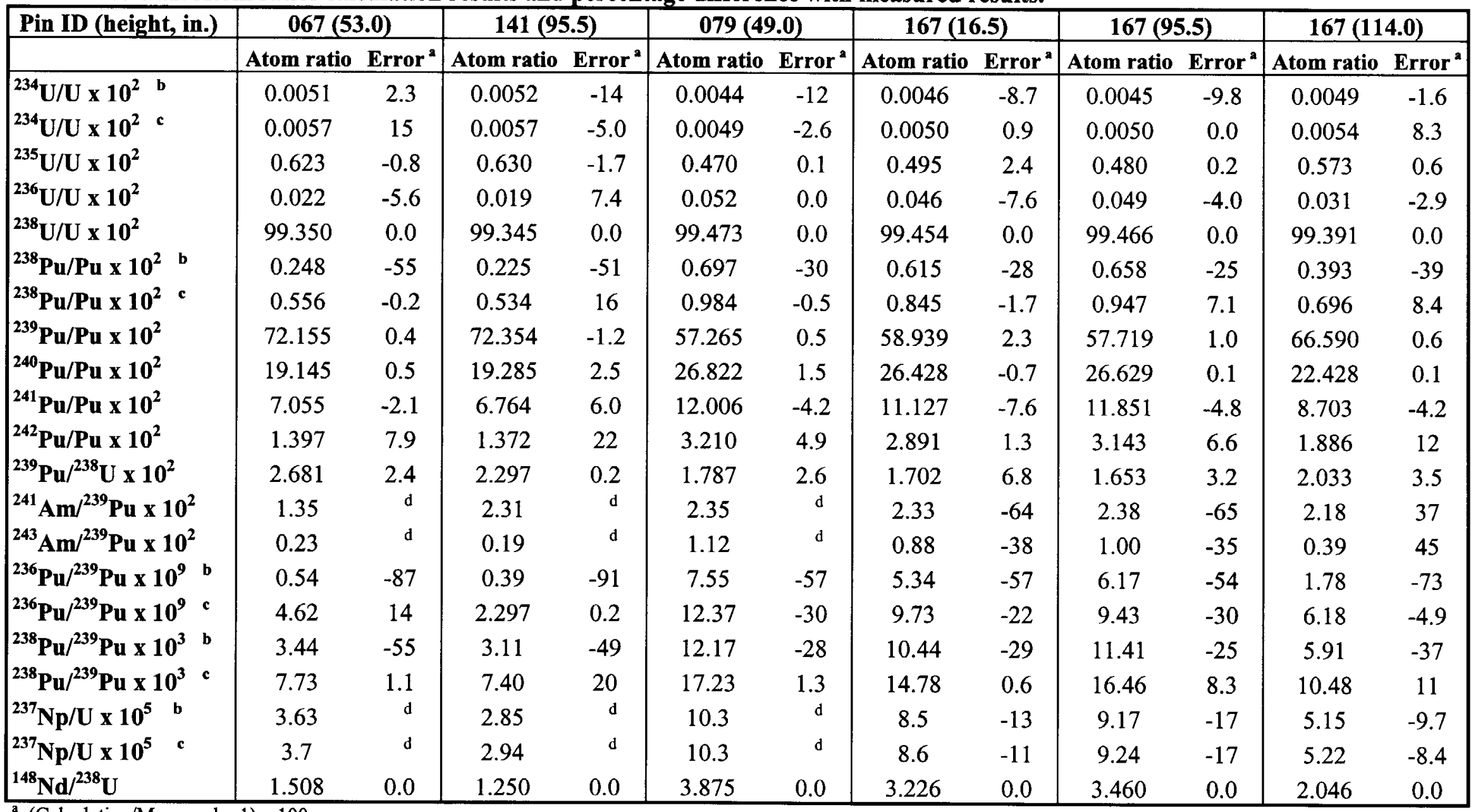

(Calculation/Measured - 1) x 100

Initial isotopic content as it is recommended in ref.[3].

c Revised isotopic content.

d No measurement.

RRC KI - IPPE 
Part 1. Calculation Analysis

of San Onofre Depletion MOX Fuel Experiment

Table 12. Measured 'isotopic content of spent fuel, gram per kilogram of initial heavy metal

\begin{tabular}{|c|c|c|c|c|c|c|}
\hline $\begin{array}{c}\text { Pin ID } \\
\text { (height, in.) }\end{array}$ & $\begin{array}{c}\mathbf{0 6 7} \\
\mathbf{( 5 3 . 0 )}\end{array}$ & $\begin{array}{c}\mathbf{1 4 1} \\
\mathbf{( 9 5 . 5 )}\end{array}$ & $\begin{array}{c}\mathbf{0 7 9} \\
\mathbf{( 4 9 . 0 )}\end{array}$ & $\begin{array}{c}\mathbf{1 6 7} \\
\mathbf{( 1 6 . 5 )}\end{array}$ & $\begin{array}{c}\mathbf{1 6 7} \\
\mathbf{( 9 5 . 5 )}\end{array}$ & $\begin{array}{c}\mathbf{1 6 7} \\
\mathbf{1 1 4 . 0}\end{array}$ \\
\hline${ }^{234} \mathrm{U}$ & 0.047 & 0.057 & 0.047 & 0.047 & 0.047 & 0.047 \\
${ }^{235} \mathrm{U}$ & 5.933 & 6.094 & 4.410 & 4.550 & 4.504 & 5.390 \\
${ }^{236} \mathrm{U}$ & 0.218 & 0.172 & 0.490 & 0.473 & 0.482 & 0.304 \\
${ }^{238} \mathrm{U}$ & 950.592 & 956.548 & 945.250 & 948.869 & 947.226 & 953.530 \\
${ }^{237} \mathrm{~Np}$ & - & - & - & 0.921 & 1.053 & 0.545 \\
${ }^{236} \mathrm{Pu}$ & 0.997 & 1.000 & 2.888 & 1.860 & 2.015 & 1.208 \\
${ }^{238} \mathrm{Pu}$ & 0.193 & 0.138 & 0.286 & 0.226 & 0.235 & 0.182 \\
${ }^{239} \mathrm{Pu}$ & 25.001 & 22.026 & 16.526 & 15.189 & 15.229 & 18.816 \\
${ }^{240} \mathrm{Pu}$ & 6.653 & 5.683 & 7.693 & 7.044 & 7.118 & 6.394 \\
${ }^{241} \mathrm{Pu}$ & 2.528 & 1.937 & 3.663 & 3.202 & 3.345 & 2.605 \\
${ }^{242} \mathrm{Pu}$ & 0.456 & 0.342 & 0.899 & 0.762 & 0.796 & 0.483 \\
${ }^{241} \mathrm{Am}$ & - & - & - & 0.997 & 1.049 & 0.302 \\
${ }^{243} \mathrm{Am}$ & - & - & - & 0.218 & 0.240 & 0.052 \\
Disintegrated & 8.379 & 7.003 & 20.738 & 17.504 & 18.678 & 11.351 \\
\hline
\end{tabular}


Part 1. Calculation Analysis

of San Onofre Depletion MOX Fuel Experiment

Table 13. Predicted isotopic content of spent fuel, gram per kilogram of initial heavy metal and percentage difference with measured results.

\begin{tabular}{|c|c|c|c|c|c|c|c|c|c|c|c|c|}
\hline Pin ID & \multicolumn{2}{|c|}{$067(53.0)$} & \multicolumn{2}{|c|}{$141(95.5)$} & \multicolumn{2}{|c|}{$079(49.0)$} & \multicolumn{2}{|c|}{$167(16.5)$} & \multicolumn{2}{|c|}{$167(95.5)$} & \multicolumn{2}{|c|}{$167(114.0)$} \\
\hline \multirow[t]{2}{*}{ Burnup } & \multicolumn{2}{|c|}{$8.239 \mathrm{MWd} / \mathrm{kgHM}$} & \multicolumn{2}{|c|}{$6.885 \mathrm{MWd} / \mathrm{kgHM}$} & \multicolumn{2}{|c|}{$20.933 \mathrm{MWd} / \mathrm{kgHM}$} & \multicolumn{2}{|c|}{$17.570 \mathrm{MWd} / \mathrm{kgHM}$} & \multicolumn{2}{|c|}{$18.799 \mathrm{MWd} / \mathrm{kgHM}$} & \multicolumn{2}{|c|}{$11.237 \mathrm{MWd} / \mathrm{kgHM}$} \\
\hline & Content & Error $^{\star}$ & Content & Error ${ }^{2}$ & Content & Error $^{2}$ & Content & Error $^{2}$ & Content & Error $^{2}$ & Content & Error $^{a}$ \\
\hline${ }^{234} \mathbf{U}^{b}$ & 0.0481 & 2.2 & 0.0489 & -14 & 0.0411 & -12 & 0.0428 & -8.7 & 0.0422 & -10 & 0.0464 & -1.6 \\
\hline${ }^{234} U^{c}$ & 0.0540 & 15 & 0.0539 & -5.1 & 0.0454 & -2.8 & 0.0470 & 0.3 & 0.0464 & -0.9 & 0.0511 & 8.3 \\
\hline${ }^{235} \mathbf{U}$ & 5.876 & -1.0 & 5.984 & -1.8 & 4.404 & -0.1 & 4.659 & 2.4 & 4.516 & 0.3 & 5.421 & 0.6 \\
\hline${ }^{236} \mathbf{U}$ & 0.206 & -5.7 & 0.184 & 7.3 & 0.489 & -0.2 & 0.437 & -7.6 & 0.463 & -3.9 & 0.295 & -3.0 \\
\hline${ }^{238} \mathbf{U}$ & 949.448 & -0.1 & 955.618 & -0.1 & 943.322 & -0.2 & 948.601 & 0.0 & 947.724 & 0.1 & 952.986 & -0.1 \\
\hline $\mathbf{U}$ & 955.578 & -0.1 & 961.835 & -0.1 & 948.255 & -0.2 & 953.740 & 0.0 & 952.745 & 0.1 & 958.750 & -0.1 \\
\hline${ }^{237} \mathbf{N p}{ }^{b}$ & 0.0345 & d & 0.0273 & $\mathrm{~d}$ & 0.0969 & $\mathrm{~d}$ & 0.0804 & -13 & 0.0870 & -17 & 0.0491 & -9.8 \\
\hline${ }^{237} \mathbf{N p}^{\mathrm{c}}$ & 0.0354 & d & 0.0281 & d & 0.0976 & d & 0.0811 & -12 & 0.0876 & -17 & 0.0499 & -8.4 \\
\hline${ }^{236} \mathrm{Pu} \times 10^{7 \mathrm{~b}}$ & 0.136 & -86 & 0.085 & -91 & 1.262 & -56 & 0.855 & -54 & 0.959 & -52 & 0.342 & -72 \\
\hline${ }^{236} \mathrm{Pu} \times 10^{7 \mathrm{c}}$ & 1.165 & 17 & 0.978 & -2.2 & 2.067 & -28 & 1.626 & -13 & 1.713 & -15 & 1.187 & -1.7 \\
\hline${ }^{238} \mathbf{P u}{ }^{b}$ & 0.087 & -55 & 0.068 & -51 & 0.205 & -28 & 0.169 & -25 & 0.179 & -24 & 0.114 & -37 \\
\hline${ }^{238} \mathbf{P u}$ & 0.197 & 2.0 & 0.163 & 17 & 0.290 & 1.7 & 0.249 & 10 & 0.258 & 10 & 0.203 & 12 \\
\hline${ }^{239} \mathbf{P u}$ & 25.560 & 2.2 & 22.042 & 0.1 & 16.924 & 2.4 & 16.216 & 6.8 & 15.731 & 3.3 & 19.457 & 3.4 \\
\hline${ }^{240} \mathrm{Pu}$ & 6.810 & 2.4 & 5.900 & 3.8 & 7.960 & 3.5 & 7.301 & 3.7 & 7.288 & 2.4 & 6.581 & 2.9 \\
\hline${ }^{241} \mathrm{Pu}$ & 2.520 & -0.3 & 2.078 & 7.3 & 3.578 & -2.3 & 3.087 & -3.6 & 3.257 & -2.6 & 2.564 & -1.6 \\
\hline${ }^{242} \mathrm{Pu}$ & 0.501 & 9.9 & 0.423 & 24 & 0.961 & 6.9 & 0.805 & 5.7 & 0.867 & 9.0 & 0.558 & 16 \\
\hline Pu & 35.588 & 2.2 & 30.605 & 1.6 & 29.713 & 2.2 & 27.658 & 4.7 & 27.401 & 2.5 & 29.363 & 3.1 \\
\hline${ }^{241} \mathrm{Am}$ & 0.348 & d & 0.512 & d & 0.401 & d & 0.381 & -62 & 0.377 & -64 & 0.428 & 42 \\
\hline${ }^{243} \mathrm{Am}$ & 0.0588 & d & 0.043 & d & 0.192 & d & 0.145 & -33 & 0.160 & -33 & 0.078 & 50 \\
\hline Disintegrated & $\mathbf{8 . 3 8 0}$ & & 7.003 & & 20.738 & & 17.504 & & 18.678 & & 11.351 & \\
\hline
\end{tabular}

(Calculation/Measured - 1) x 100

b Initial isotopic content as it is recommended in ref.[3].

c Revised isotopic content.

d No measurement. 
Several comments regarding the calculation-measurements results comparison are provided in the text that follows:

- A calculation-measured difference for the isotope should not differ substantially among different samples. However, one can see that some values of Table 13 drop out of common row. The reliability of these values seems doubtful; in particular, those of sample of 141 pin.

- Predicted plutonium content exceeds the measured one approximately by $3 \%$. It is arise nainly from error of ${ }^{239} \mathrm{Pu}$ isotope.

The consideration of balance equation shows evidently that the errors' source is the fact that ${ }^{238} \mathrm{U}$ neutron capture is too high. Fulfilled earlier critically benchmark calculations showed that in well described water-moderated lattice with $\mathrm{UO}_{2}$ and $\mathrm{MOX}$ pins thermal and resonance captures in ${ }^{238} \mathrm{U}$ could be determined with high precision. It seems that in this particular benchmark the difference between calculation model and real design is crucial, that is the negligence of influence of surrounding assemblies takes place.

Isotopic content of the main plutonium isotopes is predicted with a satisfactory precision. Nevertheless calculated-measured comparison indicates that ${ }^{241} \mathrm{Pu}$ ( $\mathrm{n}$, gamma) cross section is too high.

Predicted ${ }^{236} \mathrm{Pu}$ and ${ }^{238} \mathrm{Pu}$ contents badly differ if different initial content is used. So any conclusion about calculation error could be only done if the measurement of isotope content in fresh fuel has been fulfilled.

- For ${ }^{235} \mathrm{U}$ calculated and measured contents coincide within a limit of an experimental error, which is equal to $\sim 1 \%$.

${ }^{236} \mathrm{U}$ calculated content is less then the measured value by $\sim 3 \%$.

Additional value of ${ }^{234} \mathrm{U}$ in fresh fuel increases its content in a depleted fuel by $10 \%$. It is comparable with calculated-measured percentage difference.

- Calculated values of ${ }^{237} \mathrm{~Np}$ are a little lower than measured ones. It is possible that ${ }^{238} \mathrm{U}$ (n, $2 n$ ) cross section is slightly underestimated.

- As for the americium isotopes, an experimental error is too high to make any conclusion about precision of calculation. 


\section{CONCLUSION}

Isotopic content of a spent MOX fuel has been investigated. Fuel was irradiated in San Onofre PWR reactor. Maximum burnup is equal to $20 \mathrm{MWt} / \mathrm{kgHM}$.

Atom density relations of 13 long-lived isotopes of uranium, plutonium, neptunium and americium were measured. Measured ${ }^{148} \mathrm{Nd} /{ }^{238} \mathrm{U}$ values may be linked with burnup of pellet samples.

Computer modeling of the San Onofre experiment was carried out by means of the MCU/BURNUP Monte Carlo code. It provides a possibility of verifying both the depletion analyses code and the model of experiment description.

Analysis of the measured results showed that isotope content, in gram per kilogram of initial heavy metal, can be certainly obtained for the isotopes from the list that follows: ${ }^{235} \mathrm{U}$, ${ }^{236} \mathrm{U},{ }^{239} \mathrm{Pu},{ }^{240} \mathrm{Pu},{ }^{241} \mathrm{Pu},{ }^{242} \mathrm{Pu},{ }^{237} \mathrm{~Np}$. Quantitative calculated-measured ratios should be treated as the reference ones as the experimental precision of isotope contents for both fresh and spent fuel is not known.

Predicted value of plutonium content differs from measured one by approximately $3 \%$ (calculated is higher than measured). It is related with error of ${ }^{239} \mathrm{Pu}$ isotope.

Isotope content of plutonium and uranium is predicted with satisfactory precision.

Taking into account the requirements of reactor designers, $3 \%$ calculation error of plutonium shoud be decreased. So is desirable to continue the investigation to detect source of error of plutonium content in spent MOX fuel. At first, more complicated model of geometry might by considered. 


\section{REFERENCES}

1. The MCU-RFFUA Monte Carlo Code and Its Library Collection DLC/MCUDAT-1.0. In Neutrronics Benchmarks for the Utilization of Mixed-Oxide Fuel: Joint U.S./Russian Progress Report for Fiscal Year 1997. V. 3 - Calculations performed in the Russian Federation. p. 3-1. ORNL/TM-13603/V3. June 1998. Fissile Materials Disposition Program.

2. N.A. Alexeyev, M.I. Gurevich, D.A. Skarovsky, M.S. Yudkevich. Calculation Annalysis of the Fuel Burnup Experiment at the Quad-Cities-1 Reactor. RRC Kurchatov Institute. October 1999. Fissile Materials Disposition Program.

3. O.W. Hermann. San Onofre PWR Data for Code Validation of MOX Fuel Depletion Analyses. ORNL/TM-1999/108. September 1999.

4. Description of Methodical Basis of the TVS-M Code. See [1], p. 3-4.

5. O.W. Hermann. Benchmark of SCALE (SAS2H) Isotopic Predictions of Depletion Anasyses for San Onofre PWR MOX Fuel. ORNL/TM-1999/326. February 2000.

6. E.A. Gomin, L.V. Maiorov. The MCU Monte Carlo Code for 3D Depletion Calculation. Proceedings of International Conference on Mathematics and Computation, Reactor Physics, and Environmental Analyses in Nuclear Applications, September 27-30 1999, vol.2 pp. 997-1006, Madrid, Spain,.

7. M.S. Yudkevich. The Burnup Code for Calculation of the Change of Isotopic Composition in the Reactor During the Campaign (in Russian). Preprint RRC KI - 6048/5. Moscow. 1997. 
Part 1. Calculation Analysis

of San Onofre Depletion MOX Fuel Experiment

\section{APPENDIX}

Table 14. Percentage difference of spent fuel isotopic content calculated results by MCU/BURNUP and SCALE (SAS2H) codes with measured results

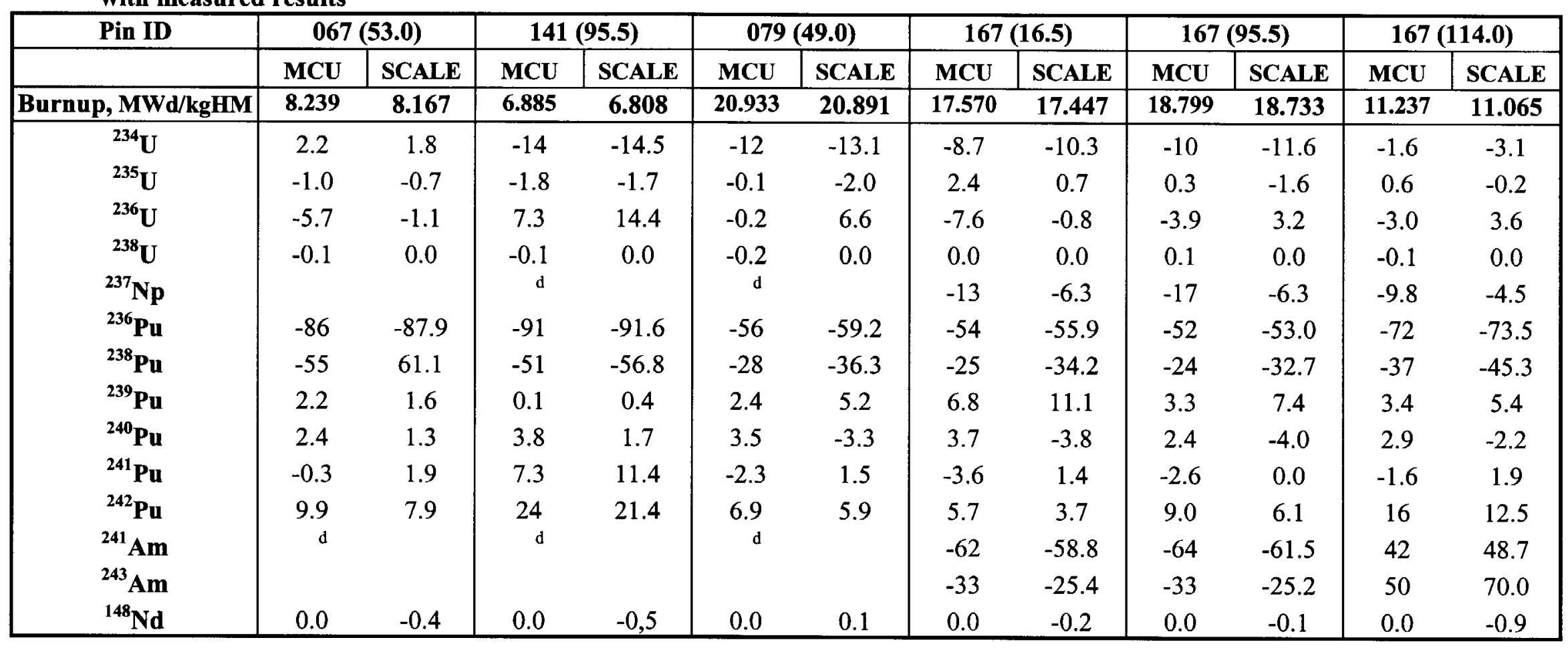


Part 2. Calculation Analysis of San Onofre PWR

MOX Fuel Depletion Data with CONKEMO Code

\section{Part 2}

Calculation Analysis of San Onofre PWR MOX Fuel Depletion Data with CONKEMO Code

Executed by

A. Belov

A.Kalashnikov

E. Kapranova

A. Tsyboulia 


\section{Introduction}

Four MOX fuel assemblies were loaded at the start of cycle 2 of San Onofre Nuclear Generation Station Unit 1 and irradiated during both cycles 2 and 3. Isotopic composition analyses were conducted by Westinghouse Electric Corporation on six sample pellets from four fuel rods of the MOX test assembly D51X.

The description of measurements of the isotopic composition in the San Onofre PWR test assembly after the irradiation are presented in [1].

This report presents calculation results of irradiation fuel isotopic composition obtained by means of code-constant package CONKEMO. The CONKEMO code results are compared with the experiment data and SCALE (SAS2H) depletion code [2] results [1].

Code-constant package CONKEMO was specially developed in SSC RF IPPE for reference burnup calculations. This package includes the following basic codes:

- CONSYST prepares the group (299 groups) cross-sections of medium based on ABBN-93 neutron data library [3];

- KENO-V.a used for neutronic flux calculations in an arbitrary geometry (including hexagonal one) by the Monte Carlo method;

- ORIGEN performs isotope evaluation calculations;

- MAYAK provides the joint work of the codes in the complex, information flows, process the results.

KENO-V.a [4] is a part of American SCALE 4.3 system and performs precision calculations in arbitrary three-dimensional geometry by Monte Carlo method.

ORIGEN-S [5] is also a part of the SCALE 4.3 system. Cross-sections from original ORIGEN libraries are updated during the calculations.

An extended description of CONKEMO code complex is given in [6].

\section{Calculation Model}

The detailed description of D51X irradiation conditions, its design and composition is given in [1]. Only some data necessary for calculational model description taken from [1] is given below.

Locations of MOX fuel assemblies during cycles 2 and 3 in San Onofre reactor core are shown on Figure 1. Arrangement of the pins in experimental assembly D51X taken for post-irradiation studies is shown on Figure 2. Basic parameters of measured MOX spent fuel samples and San Onofre operating data are given in Table 1 and Table 2.

It is clear from Figure 1 that D51X experimental assembly located close to the border of the core. In the calculational model, however, the assembly was supposed to be isolated with mirror boundary conditions at the middle of the water gap between the assemblies. During burnup calculations of each sample the value of assembly power was chosen in condition to have fuel sample pellet burnup equal to the experimental one. At the same time, the temperatures of fuel and moderator for the whole assembly were considered to be the same as for the given sample. 
Part 2. Calculation Analysis of San Onofre PWR

MOX Fuel Depletion Data with CONKEMO Code

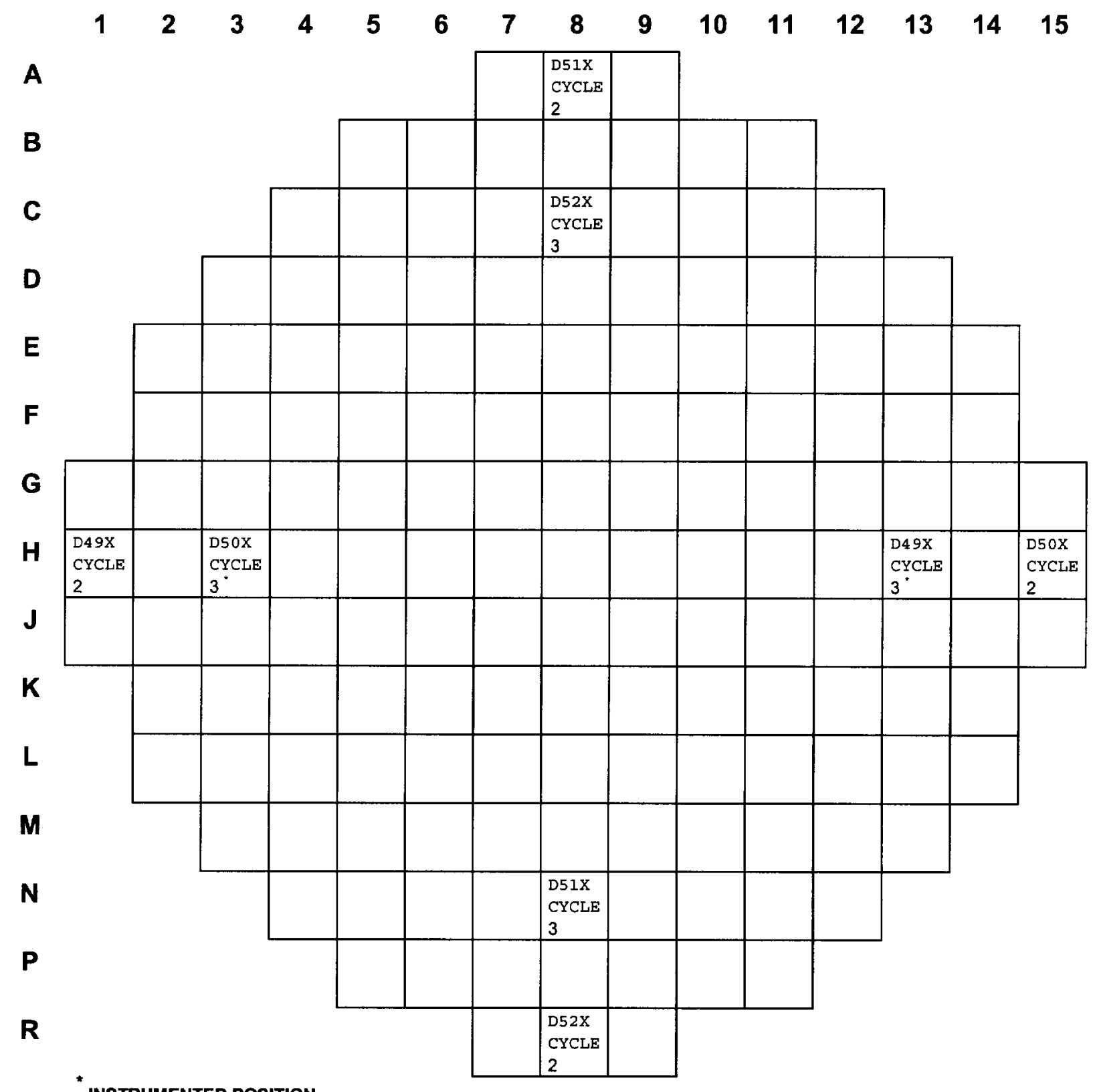

INSTRUMENTED POSITION

Figure 1. Location of plutonium demonstration assemblies in San Onorfe cycle 2 and cycle 3 
TO CENTER OF CORE (CYCLE 2)

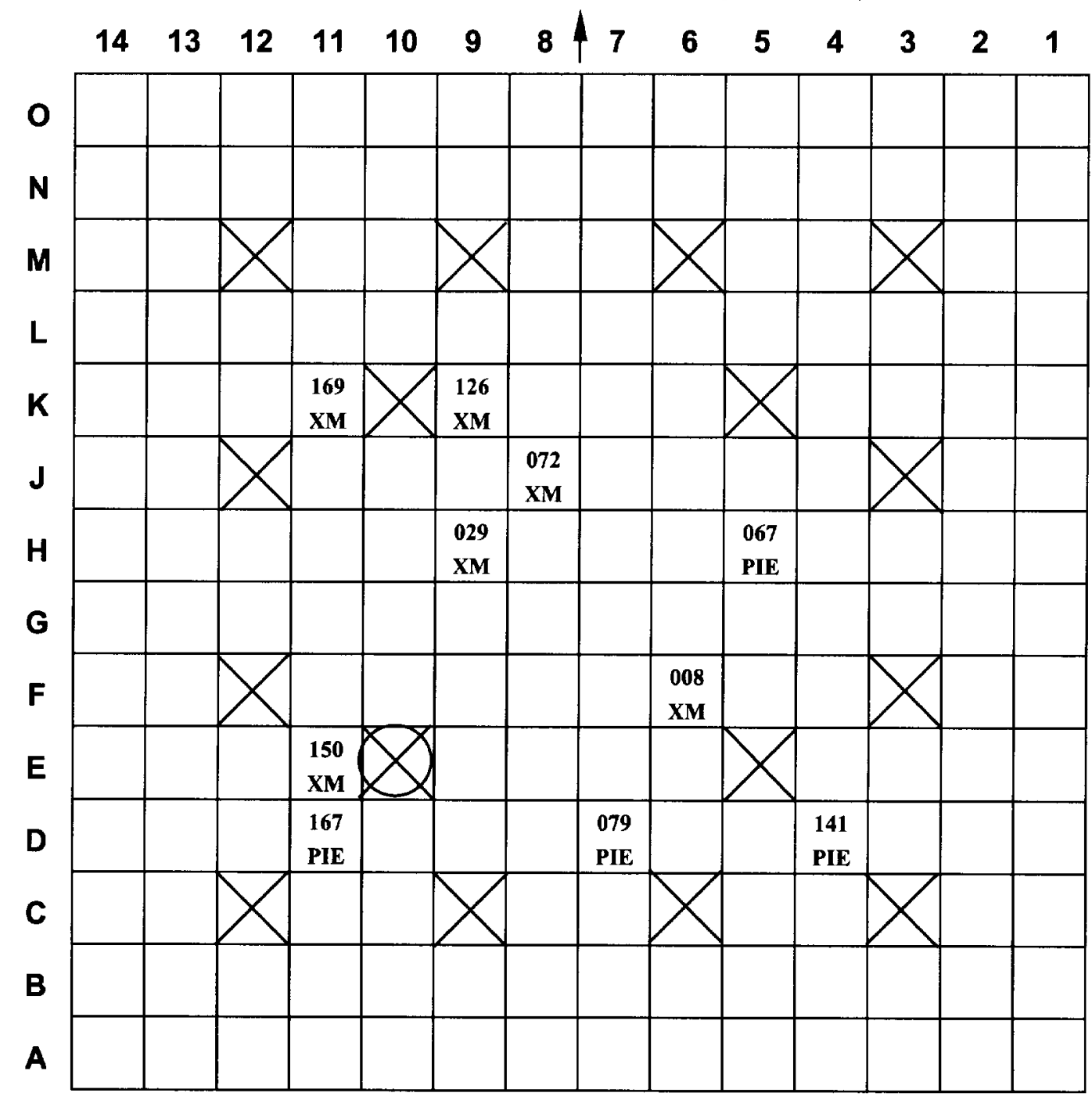

Y CORNER

TO CENTER OF CORE (CYCLE 3)

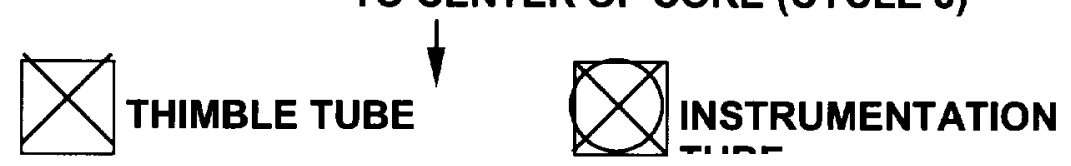

XM - ON SITE EXAMINATION

PIE - HOT CELL EXAMINATION

Figure 2. Location of rods removed from San Onorfe Plutonium Demonstration Assembly D51X for post-irradiation examination 
Table 1

Basic parameters of measured MOX spent fuel samples of assembly D51X

\begin{tabular}{|c|c|c|c|c|c|c|}
\hline \multirow{2}{*}{$\begin{array}{l}\text { Case } \\
\text { No. }\end{array}$} & \multirow{2}{*}{$\begin{array}{l}\text { Pin } \\
\text { ID }\end{array}$} & \multicolumn{2}{|c|}{ Initial enrichment } & \multirow{2}{*}{$\begin{array}{l}\text { Location } \\
\mathrm{ht}^{\mathrm{a}} \text { (in.) }\end{array}$} & \multicolumn{2}{|c|}{ Burnup $^{b, c}$} \\
\hline & & (at. $\%{ }^{235} \mathrm{U}$ ) & (wt \% fissile $\mathrm{Pu}$ ) & & Cycle 1 & Total \\
\hline 1 & 067 & 0.72 & 3.31 & 53.0 & 8.167 & 8.167 \\
\hline 2 & 141 & 0.72 & 2.84 & 95.5 & 6.808 & 6.808 \\
\hline 3 & 079 & 0.72 & 3.10 & 49.0 & 7.015 & 20.891 \\
\hline 4 & 167 & 0.72 & 2.84 & 16.5 & 5.999 & 17.447 \\
\hline 5 & 167 & 0.72 & 2.84 & 95.5 & 6.434 & 18.713 \\
\hline 6 & 167 & 0.72 & 2.84 & 114.0 & 3.843 & 11.065 \\
\hline
\end{tabular}

Table 1 (continuation)

\begin{tabular}{|c|c|c|c|c|c|c|}
\hline \multirow{2}{*}{$\begin{array}{c}\text { Case } \\
\text { No. }\end{array}$} & \multirow{2}{*}{ Pin } & \multicolumn{2}{|c|}{ Fuel pellet powers } & \multicolumn{3}{c|}{ Temperature, K } \\
\cline { 3 - 6 } & & \multicolumn{2}{|c|}{ MW/MTHM } & \multicolumn{2}{|c|}{ Fuel } & \multirow{2}{*}{ Mederator } \\
\cline { 3 - 6 } & & Cycle 1 & Cycle 2 & Cycle 1 & Cycle 2 & \\
\hline \hline 1 & 067 & 20.266 & - & 744 & - & 575 \\
2 & 141 & 16.894 & - & 713 & - & 585 \\
3 & 079 & 17.406 & 30.232 & 718 & 839 & 574 \\
4 & 167 & 14.885 & 24.942 & 695 & 787 & 566 \\
5 & 167 & 15.965 & 26.751 & 705 & 805 & 585 \\
6 & 167 & 9.536 & 15.735 & 650 & 703 & 590 \\
\hline
\end{tabular}

${ }^{\text {a }}$ Height above bottom of active fuel.

${ }^{\mathrm{b}}$ Determination from ${ }^{148} \mathrm{Nd}$ measurements.

${ }^{\mathrm{c}}$ Megawatt days per metric ton heavy metal (U+Pu).

${ }^{\mathrm{d}}$ Calculated directly from the burnup and cycle time. 
${ }^{\mathrm{e}}$ In contradiction with [1], different moderator temperatures were considered for different studied samples. At the same time it was considered that moderator temperature is growing proportionally depending on the core height and that water heating was equal $30^{\circ} \mathrm{C}$.

Table 2

San Onofre operating regime

\begin{tabular}{|c|c|c|c|}
\hline $\begin{array}{l}\text { Operating data type, } \\
\text { Pin ID } \\
\\
\text { (height, in) }\end{array}$ & Units & Cycle 2 & Cycle 1 \\
\hline Cycle times & & $11 / 18 / 70$ & $3 / 1 / 72$ \\
\hline Startup date & & $12 / 26 / 71$ & $6 / 2 / 73$ \\
\hline Shundown date & & & \\
\hline Uptime & Days & 403 & 459 \\
\hline Downtime & Days & 66 & $-{ }^{a}$ \\
\hline Shutdown to analysis times ${ }^{a}$ & Days & & \\
\hline $067(53.0)$ & & 717 & - \\
\hline $141(95.5)$ & & 719 & - \\
\hline $079(49.0)$ & & & 194 \\
\hline $167(16.5)$ & & & 187 \\
\hline $167(95.5)$ & & & 187 \\
\hline $167(114.0)$ & & & 192 \\
\hline
\end{tabular}

${ }^{\text {a }}$ Time from cycle shutdown to sample analysis.

Nuclide concentrations were calculated for the moment of measurement. There were 8 time steps for the first cycle and 12 of them for the second one. Shutdown time between cycles (66 days) and shutdown to analysis time were passed through during one calculational step with very low power. Decay of ${ }^{241} \mathrm{Pu}$ and formation of ${ }^{241} \mathrm{Am}$ during time period from initial Plutonium isotopic composition measurement to the start of assembly irradiation in the reactor (605 days) were taken into account in the starting data.

Sample 141, irradiated in the reactor only during the second cycle and which located closest to the blanket was chosen to estimate the influence of neutron spectrum on spent fuel isotopic composition in reactor and isolated assembly. Burnup calculations in this sample 
were performed additionally in a model which approximately takes into account the leakage of neutrons to the blanket, shown on Figure 3.

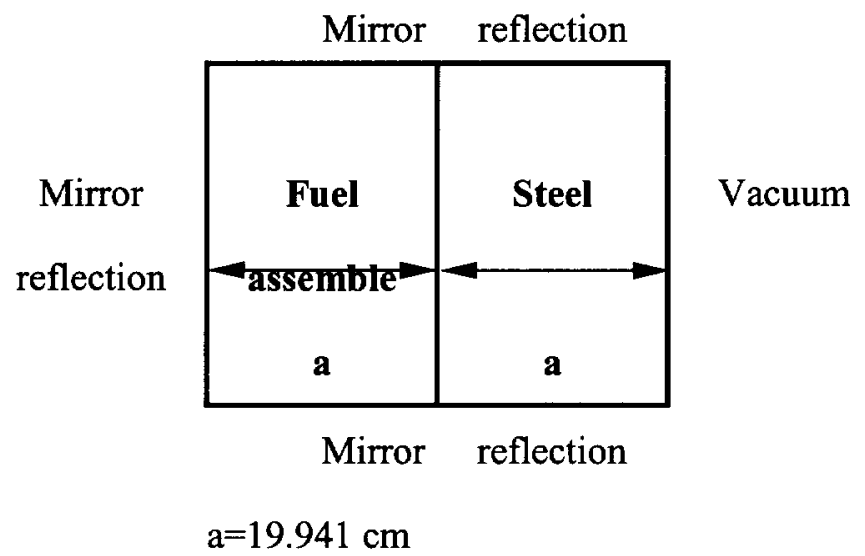

Figure 3. Calculational model for estimation of the influence of neutron spectrum on spent fuel isotopic composition in reactor and isolated assembly 


\section{Calculation results}

Ratios of nuclide densities (milligrams per gram of initial heavy metal) calculated with CONKEMO and SCALE(SAS2H) codes at time of analysis to the measured densities are presented in Table Al of the Appendix. Ratios of calculated and experimental densities of nuclides averaged over 6 samples are shown on Figure 4.

Percentage differences between computed and measured nuclide densities for fuel samples and values averaged over all samples of Assembly D51X are shown in Table 3.

It is clear from Figure 4 and Table 3 that CONKEMO calculation is in a little better agreement with the experiment then SCALE(SAS2H) calculation. The exceptions are ${ }^{237} \mathrm{~Np}$, ${ }^{241} \mathrm{Pu}$ and ${ }^{243} \mathrm{Am}$ for which the difference between calculation and experiment in case of CONKEMO code is significantly higher then one for SCALE(SAS2H) code. ${ }^{236} \mathrm{Pu}$ has the greatest difference of calculations from the experiment for both codes (a few times lower for both codes). Accumulation of ${ }^{238} \mathrm{Pu}$ for both codes is about 1.7 times lower, accumulation of ${ }^{241} \mathrm{Am}$ - 1.3 times lower. Accumulation of ${ }^{237} \mathrm{~Np}$ is about 1.3 times lower in case of CONKEMO code.

Ratios of calculated isotope densities to experimental ones averaged over 4 samples with MOX fuel in Quad Sities-1 reactor and over 6 samples in San Onofre reactor are presented on Figure 5. Calculational data for Quad Cities-1 reactor are taken from [7]. In both cases the calculations were performed with CONKEMO code. 
Part 2. Calculation Analysis of San Onofre PWR

MOX Fuel Depletion Data with CONKEMO Code

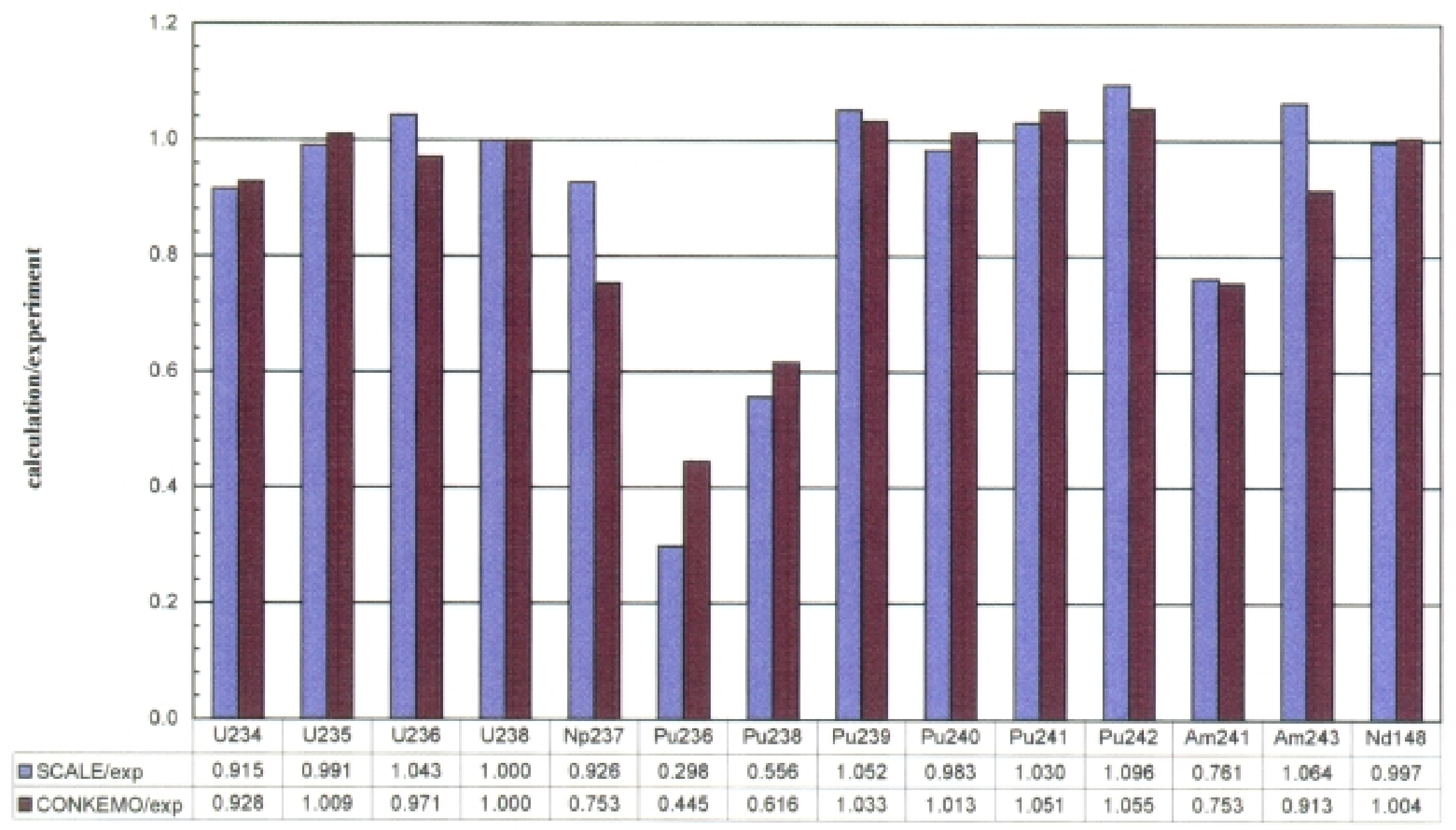

Figure 4. Average c/e for the isotope densities of six samples 
Part 2. Calculation Analysis of San Onofre PWR

MOX Fuel Depletion Data with CONKEMO Code

Percentage difference between measured and computed nuclide

Table 3

for fuel samples and averages from assembly D51X

\begin{tabular}{|c|c|c|c|c|c|c|c|c|c|c|c|c|}
\hline \multirow[t]{2}{*}{ Nuclide } & \multicolumn{6}{|c|}{ Samples, (CONKEMO/exp -1)*100 } & \multicolumn{3}{|c|}{ CONKEMO } & \multicolumn{3}{|c|}{ SCALE } \\
\hline & 067 & 141 & 079 & $167(16.5)$ & $167(95.5)$ & $167(114)$ & average & st. deviation ${ }^{\mathbf{a}}$ & st. dev. of av. ${ }^{b}$ & average & st. deviation $^{\mathrm{a}}$ & st. dev. of av. $^{b}$ \\
\hline${ }^{234} \mathrm{U}$ & 2.562 & -13.871 & -11.413 & -8.339 & -10.221 & -2.192 & -7.2 & 6.2 & 2.5 & -8.5 & 6.4 & 2.6 \\
\hline${ }^{235} \mathrm{U}$ & -0.441 & -1.404 & 1.090 & 3.389 & 1.377 & 1.549 & 0.9 & 1.7 & 0.7 & -0.9 & 1.1 & 0.4 \\
\hline${ }^{236} \mathrm{U}$ & -6.372 & 7.396 & -1.127 & -8.990 & -4.334 & -4.183 & -2.9 & 5.7 & 2.3 & 4.3 & 5.7 & 2.3 \\
\hline${ }^{238} \mathrm{U}$ & -0.010 & 0.008 & 0.030 & 0.040 & 0.012 & -0.007 & 0.0 & 0.0 & 0.0 & 0.0 & 0.0 & 0.0 \\
\hline${ }^{236} \mathrm{Pu}$ & -80.527 & -87.373 & -38.687 & -38.353 & -28.602 & -59.280 & -55.5 & 24.3 & 9.9 & -70.2 & 16.7 & 6.8 \\
\hline${ }^{238} \mathrm{Pu}$ & -56.047 & -52.026 & -29.484 & -28.273 & -25.849 & -38.900 & -38.4 & 12.9 & 5.3 & -44.4 & 12.2 & 5.0 \\
\hline${ }^{239} \mathrm{Pu}$ & 2.282 & 0.511 & 2.032 & 5.801 & 4.603 & 4.571 & 3.3 & 2.0 & 0.8 & 5.2 & 3.9 & 1.6 \\
\hline${ }^{240} \mathrm{Pu}$ & 1.636 & 2.349 & 1.355 & 1.366 & 0.432 & 0.786 & 1.3 & 0.7 & 0.3 & -1.7 & 2.6 & 1.0 \\
\hline${ }^{241} \mathrm{Pu}$ & 3.309 & 12.910 & 3.909 & 2.595 & 3.085 & 4.897 & 5.1 & 3.9 & 1.6 & 3.0 & 4.2 & 1.7 \\
\hline${ }^{242} \mathrm{Pu}$ & 4.308 & 18.359 & 0.719 & -0.082 & 1.223 & 8.204 & 5.5 & 7.0 & 2.9 & 9.6 & 6.5 & 2.6 \\
\hline${ }^{237} \mathrm{~Np}$ & & & & -25.897 & -27.297 & -20.966 & -24.7 & 3.3 & 1.9 & -7.4 & 3.5 & 2.0 \\
\hline${ }^{241} \mathrm{Am}$ & & & & -59.539 & -61.934 & 47.303 & -24.7 & 62.4 & 36.0 & -23.9 & 62.9 & 36.3 \\
\hline${ }^{243} \mathrm{Am}$ & & & & -38.044 & -36.510 & 48.579 & -8.7 & 49.6 & 28.6 & 6.4 & 55.0 & 31.8 \\
\hline${ }^{148} \mathrm{Nd}$ & 0.296 & 0.175 & 1.031 & 0.574 & 0.785 & -0.313 & 0.4 & 0.5 & 0.2 & -0.3 & 0.4 & 0.1 \\
\hline
\end{tabular}

${ }^{a}$ One standard deviation in individual data points

${ }^{\mathrm{b}}$ One standard deviation of average
Average $=\left[\overline{\left(\frac{c}{e}\right)}-1\right] \cdot 100 \%$,
St. deviation $=\sqrt{\sum_{i=1}^{I}\left[\frac{c_{i}}{e_{i}}-\left(\frac{c}{e}\right)\right]^{2} /(I-1)}$
St. deviation of average $=\sqrt{\sum_{i=1}^{1}\left[\frac{c_{i}}{e_{i}}-\left(\frac{c}{e}\right)\right]^{2} / I \cdot(I-1)}$,
$\overline{\left(\frac{c}{e}\right)}=\frac{1}{I} \cdot \sum_{i=1}^{I}\left(\frac{\text { calc }}{\exp }\right)_{i}$,
I - experiment number 
Part 2. Calculation Analysis of San Onofre PWR

MOX Facl Depletion Data with CONKEMO Code

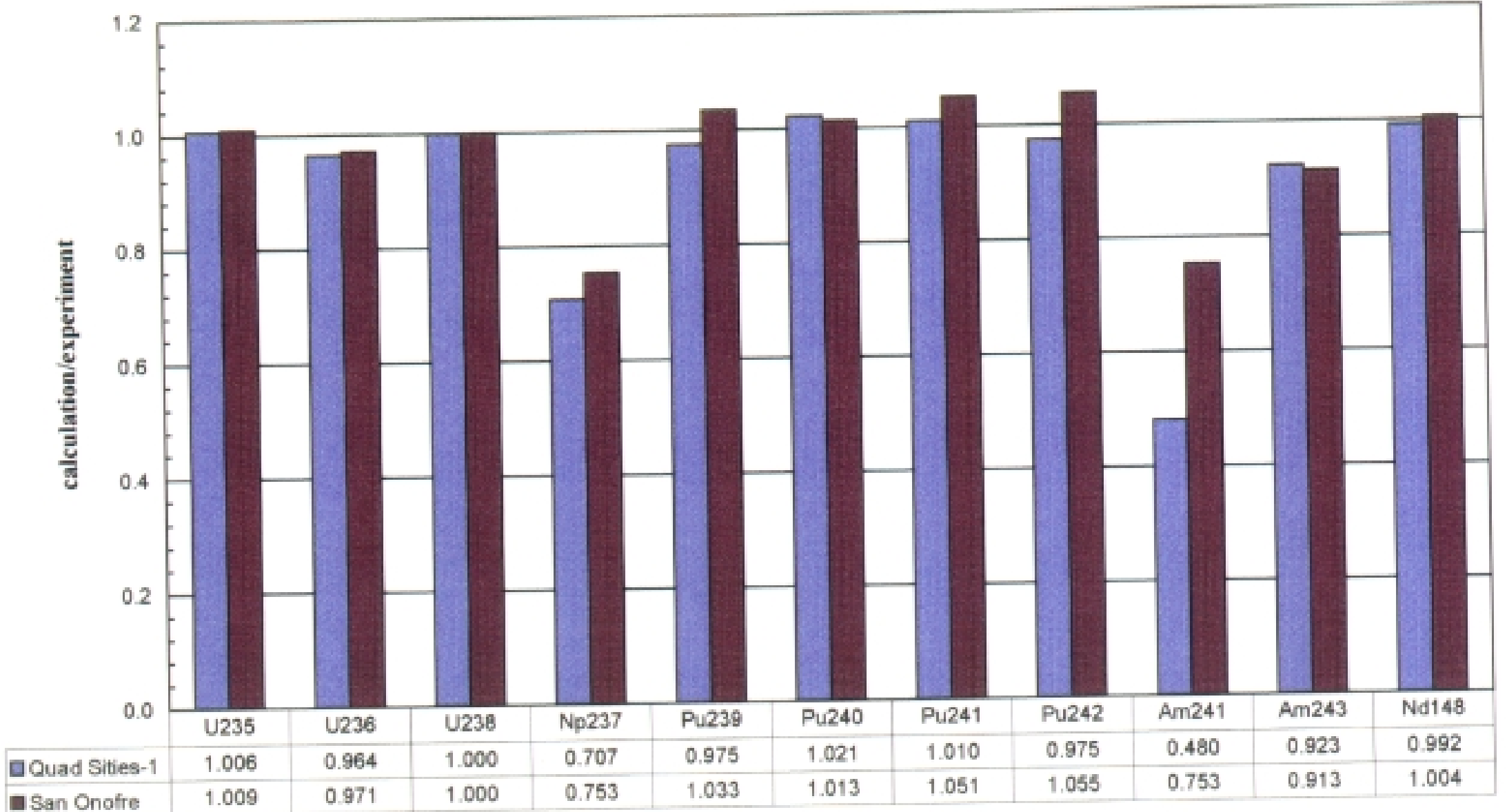

Figure 5. Average c/e for the isotope densities of Quad Sities-1 and San Onofre MOX samples (CONKEMO code) 
As it is clear from Figure 5, in both cases ${ }^{235} \mathrm{U}$ concentration in CONKEMO calculations is (0.6-0.9) \% higher, ${ }^{236} \mathrm{U}$ concentration is (3-4) \% lower. In both cases ${ }^{240} \mathrm{Pu}$ and ${ }^{241} \mathrm{Pu}$ concentrations are higher $\left(1 \%-2 \%\right.$ for ${ }^{240} \mathrm{Pu}$ and $1 \%-5 \%$ for $\left.{ }^{241} \mathrm{Pu}\right)$. Calculated concentrations of ${ }^{239} \mathrm{Pu}$ and ${ }^{242} \mathrm{Pu}$, in average are close to the experiment. Concentrations of ${ }^{237} \mathrm{~Np}$, ${ }^{243} \mathrm{Am}$ and, particularly, ${ }^{241} \mathrm{Am}$ are significantly lower.

Hence we see correlation of differences between calculations and experiment in both reactors. It may serve a base for neutron cross section correction. However, in some cases, experimental errors could be the source of differences (for example, lack of ${ }^{241} \mathrm{Am}$ content in fresh fuel data for Quad Cities-1 reactor samples or low precision of the measurements). Calculational analysis of possibly bigger number of measurements by the same set of codes is required for more reliable conclusions concerning the sources of differences between calculations and experiment.

Ratios of calculated nuclide concentrations in sample 141 at the moment of measurement received in the model with neutron leakage (see Figure 3) and in the model of isolated assembly are presented in Table 4.

Table 4

Ratios of nuclide concentrations in sample 141 calculated in models with and without neutron leakage

\begin{tabular}{||c|c|}
\hline Nuclide & $\begin{array}{c}\text { With leakage } \\
\text { without leakage }\end{array}$ \\
\hline \hline${ }^{234} \mathrm{U}$ & 0.999 \\
${ }^{235} \mathrm{U}$ & 0.999 \\
${ }^{236} \mathrm{U}$ & 1.004 \\
${ }^{238} \mathrm{U}$ & 1.000 \\
\hline${ }^{236} \mathrm{Pu}$ & 0.985 \\
${ }^{238} \mathrm{Pu}$ & 0.998 \\
${ }^{239} \mathrm{Pu}$ & 1.001 \\
${ }^{240} \mathrm{Pu}$ & 1.001 \\
${ }^{241} \mathrm{Pu}$ & 0.999 \\
${ }^{242} \mathrm{Pu}$ & 0.998 \\
\hline${ }^{148} \mathrm{Nd}$ & 1.000 \\
\hline
\end{tabular}

It is clear from Table 4 that taking into account the neutron leakage in the considered model almost did not change the calculated values of nuclide concentrations. 


\section{Conclusions}

1. CONKEMO calculations are in a little better agreement with the experiment then SCALE(SAS2H) calculations. The exceptions are ${ }^{237} \mathrm{~Np},{ }^{241} \mathrm{Pu}$ and ${ }^{243} \mathrm{Am}$ for which the difference between calculation and experiment in case of CONKEMO code is significantly higher then one for SCALE(SAS2H) code. ${ }^{236} \mathrm{Pu}$ has the greatest difference of calculations from the experiment for both codes (a few times lower). Accumulation of ${ }^{238} \mathrm{Pu}$ for both codes is about 1.7 times lower, accumulation of ${ }^{241} \mathrm{Am}-1.3$ times lower. Accumulation of ${ }^{237} \mathrm{~Np}$ is about 1.3 times lower in case of CONKEMO code.

2. Comparison of ratios of calculated isotope densities to experimental ones averaged over 4 samples with MOX fuel in Quad Cities-1 reactor and over 6 samples in San Onofre reactor shows that correlation of differences between calculations and experiment in both reactors exists for most of the isotopes. It may serve a base for neutron cross section correction. However, in some cases, experimental errors could be the source of differences (for example, lack of ${ }^{241} \mathrm{Am}$ content in fresh fuel data for Quad Cities-1 reactor samples or low precision of the measurements). Calculational analysis of possibly bigger number of measurements by the same set of codes is required for more reliable conclusions concerning the sources of differences between calculations and experiment.

\section{References}

1. O.W. Hermann. Benchmark of SCALE (SAS2H) Isotopic Predictions of Depletion Analyses for San Onofre PWR MOX Fuel. ORNL/TM-1999/326, February 2000.

2. O.W. Hermann and C.V. Parks. "SAS2H: A Couped One-Dimensional Depletion and Shielding Analysis Code." Sect. S2 of SCALE: A Modular Code System for Performing Standardized Computer Analyses for Licensing Evaluation, NUREG/CR-0200, Rev. 4 (ORNL/NUREG/CSD-2/R4), Vols. I, II and III (March 1997).

3. Мантуров Г.Н., Николаев М.Н., Цибуля А.М. "Система групповых констант БНАБ-93. Верификационный отчет № 1. Рекомендованные справочные данные." Москва 1995.

4. L.M. Petrie, N.F. Landers. KENO-V.a: An Improved Monte Carlo Criticality Program with Supergrouping. SCALE 4.3. Vol. 2, Section F11, 1995.

5. O.W. Hermann, R.M. Westfall. ORIGEN-S: SCALE System Module to Calculate Fuel Depletion, Actinide Transmutation, Fission Product Buildup and Decay, and Association Source Terms. SCALE 4.3, Vol. 2, Section F7, 1995.

6. Z.N. Chizhikova, A.G. Kalashnikov et all. Verification Calculation Results to Validate the Procedures and Codes for Pin-by-Pin Power Computation in VVER Type Reactors with MOX Fuel Loading. ORNL/SUB/98-851399398V-3, 1998.

7. A. Belov, A. Kalashnikov, E. Kapranova, A. Tsyboulia. Calculation Analysis of the Fuel Burnup Experiment at the Quad Cities-1 Reactor with CONKEMO Code. Joint Technical Meeting on Trilateral (Russian-French-German) and Bilateral (Russian-American) Agreements for Weapons-Grade Disposition in Reactors VVER-1000 with the Participation of Italian Specialists. July 24-28, 2000 RRC Kurchatov Institute. Moscow. 
Part 2. Calculation Analysis of San Onofre PWR

MOX Fuel Depletion Data with CONKEMO Code

\section{Appendix}

Ratios of calculated atom densities to the measured ones

Table A1

\begin{tabular}{|c|c|c|c|c|c|c|c|c|c|c|c|c|c|c|c|}
\hline \multirow{2}{*}{$\begin{array}{l}\text { Pin num- } \\
\text { ber, } \\
\text { length } \\
\text { (inch) }\end{array}$} & & \multicolumn{14}{|c|}{ Nuclide } \\
\hline & & ${ }^{234} \mathrm{U}$ & ${ }^{235} \mathrm{U}$ & ${ }^{236} \mathrm{U}$ & ${ }^{238} \mathrm{U}$ & ${ }^{237} \mathrm{~Np}$ & ${ }^{236} \mathrm{Pu}$ & ${ }^{238} \mathrm{Pu}$ & ${ }^{239} \mathrm{Pu}$ & ${ }^{240} \mathrm{Pu}$ & ${ }^{241} \mathrm{Pu}$ & ${ }^{242} \mathrm{Pu}$ & ${ }^{241} \mathrm{Am}$ & ${ }^{243} \mathrm{Am}$ & ${ }^{148} \mathrm{Nd}$ \\
\hline 067 & SCALE/exp & 1.018 & 0.993 & 0.989 & 1.000 & & 0.121 & 0.389 & 1.016 & 1.013 & 1.019 & 1.079 & & & 0.996 \\
\hline 53.0 & CONKEMO/exp & 1.026 & 0.996 & 0.936 & 1.000 & & 0.195 & 0.440 & 1.023 & 1.016 & 1.033 & 1.043 & & & 1.003 \\
\hline 141 & SCALE/exp & 0.855 & 0.983 & 1.144 & 1.000 & & 0.084 & 0.432 & 1.004 & 1.017 & 1.114 & 1.213 & & & 0.995 \\
\hline 95.5 & CONKEMO/exp & 0.861 & 0.986 & 1.074 & 1.000 & & 0.126 & 0.480 & 1.005 & 1.023 & 1.129 & 1.184 & & & 1.002 \\
\hline 079 & SCALE/exp & 0.869 & 0.980 & 1.066 & 1.000 & & 0.408 & 0.637 & 1.052 & 0.967 & 1.015 & 1.059 & & & 1.001 \\
\hline 49.0 & CONKEMO/exp & 0.886 & 1.011 & 0.989 & 1.000 & & 0.613 & 0.705 & 1.020 & 1.014 & 1.039 & 1.007 & & & 1.010 \\
\hline 167 & SCALE/exp & 0.897 & 1.007 & 0.992 & 1.000 & 0.937 & 0.441 & 0.658 & 1.111 & 0.962 & 1.014 & 1.037 & 0.412 & 0.746 & 0.998 \\
\hline 16.5 & CONKEMO/exp & 0.917 & 1.034 & 0.910 & 1.000 & 0.741 & 0.616 & 0.717 & 1.058 & 1.014 & 1.026 & 0.999 & 0.405 & 0.620 & 1.006 \\
\hline 167 & SCALE/exp & 0.883 & 0.984 & 1.032 & 1.000 & 0.887 & 0.470 & 0.673 & 1.074 & 0.960 & 1.000 & 1.061 & 0.385 & 0.748 & 1.000 \\
\hline 95.5 & CONKEMO/exp & 0.898 & 1.014 & 0.957 & 1.000 & 0.727 & 0.714 & 0.742 & 1.046 & 1.004 & 1.031 & 1.012 & 0.381 & 0.635 & 1.008 \\
\hline 167 & SCALE/exp & 0.969 & 0.999 & 1.036 & 1.000 & 0.955 & 0.265 & 0.547 & 1.054 & 0.978 & 1.019 & 1.125 & 1.487 & 1.700 & 0.990 \\
\hline 114 & CONKEMO/exp & 0.978 & 1.015 & 0.958 & 1.000 & 0.790 & 0.407 & 0.611 & 1.046 & 1.008 & 1.049 & 1.082 & 1.473 & 1.486 & 0.997 \\
\hline
\end{tabular}




\section{Comments on Calculation Analysis of San Onofre Depletion MOX Fuel Experiment by M. D. DeHart and R. J. Ellis, Oak Ridge National Laboratory}

The title of the document is in fact the title of Part 1; the title of Part 2 is different. Having two parts with different titles leads to the two parts being disjointed. To fully merge both parts into a single cohesive document, there should be an overall Table of Contents, List of Tables and List of Figures at the beginning of the main document. There should be a consistent page, table, figure, appendix, and reference numbering strategy.

In the Abstract, we suggest that "it is arise mainly from errors of ${ }^{239} \mathrm{Pu}$ isotope" be changed to "The discrepancy arises mainly from error in the ${ }^{239} \mathrm{Pu}$ concentration."

\section{Review of Part 1. Calculation Analysis of San Onofre Depletion MOX Fuel Experiment}

1. Page 5, first paragraph. "San" is misspelled as "Sun."

2. Page 6 , fourth paragraph. It is not certain what is meant by "does not rise any doubt." Verification of a database can help to determine errors in the database, but it does not eliminate them. At a minimum, a reference for these studies should be provided.

3. Page 6, fourth paragraph. Although Monte Carlo does allow direct modeling of the nominal assembly design, it does not accurately represent temperatures, densities, etc., which can only be estimated. Furthermore, the model does not account for cladding creep down, fuel swelling, etc. It is only an idealized model.

4. Page 6, Abstract. Change "Sample's burnup values" to "Sample burnup values."

5. Page 12, Fig. 2. The word "betta" should be "beta."

6. Page 12, Fig. 2. The word "alpha" in the inset should be moved down. The alpha-decay from ${ }^{242} \mathrm{Cm}$ to ${ }^{238} \mathrm{Pu}$ is a large contributor to the ${ }^{238} \mathrm{Pu}$ concentration. It is often erroneously overlooked. What is the "**" in "for ${ }^{242} \mathrm{Am}$ *" signifying? Is this supposed to be the metastable (m) state?

7. Page 7, last sentence. The uranium assembly is described in a revision of Ref. 3, ORNL/TM-1999/108R (Appendix B).

8. Page 7, Table 1. After "soluble boron," what does "wt" mean? Ppm is not a mass.

9. Page 7, Table 1. Was the MOX fuel assumed to be a homogenized blend of uranium and plutonium isotopes?

10. Page 9, Table 3. The nuclide symbol names are formatted better elsewhere in the document, as superscripted A-values.

11. Page 10, Table 4. For the units, "kw/ft," it is ORNL policy to change these to SI equivalent, and also, "W" should be in capitals.

12. Page 10, Table 5. The isotope ${ }^{146} \mathrm{Nd}$ should be ${ }^{148} \mathrm{Nd}$. 
13. Page 11, third paragraph. The phrase "reach lines" should likely be "bold lines."

14. Page 11, sixth paragraph. A reference to previous studies should be provided.

15. Page 11, Sect. 3.2, first paragraph. Why was a white boundary condition used rather than a reflective one? This removes all angular data. It could be that this is appropriate because surrounding assemblies are different. However, it is known that there will be a net leakage of thermal neutrons from an LEU assembly to an adjacent MOX assembly. The data from the revision to Ref. 3 should be used to model (at least approximately) the surrounding LEU assemblies.

16. Page 11, Sect. 3.2, first paragraph. The phrase "absolutely identical" is too strong (see comment no. 4).

17. Page 11, Sect. 3.2, second paragraph. We suggest that wording is changed from "a assembly environment" to "surrounding assemblies."

18. Page 12. The word "betta" should be "beta."

19. Page 13, paragraphs 2 and 4 . The isotope ${ }^{146} \mathrm{Nd}$ should be ${ }^{148} \mathrm{Nd}$.

20. Page 13. The discussion of ${ }^{234} \mathrm{U}$ related to alpha-decay of ${ }^{238} \mathrm{Pu}$.... It should in turn mention the important alpha-decay of ${ }^{242} \mathrm{Cm}$ to ${ }^{238} \mathrm{Pu}$.

21. Page 14, Fig. 4. The shape of the curve through the four data points seems indicative of a bad polynomial fit. It is not a good fit as ${ }^{148} \mathrm{Nd} / 238 \mathrm{U}$ goes to zero. The upshot at zero is anomalous.

22. Page 15, Sect 3.4. The phrase "initial nuclear density" should be changed to "initial number density."

23. Page 14, Figs. 3 and 4. Are these fits from least-squares analyses? If so, are they fitted to some function that is derived from studying the production/depletion chains for these nuclides? The comment in paragraph 5 would seem to indicate that this procedure was not followed.

24. Page 15, Table 6. Superscripts "a" and "b" are not defined, but from the context of the report, it is deduced that "a" refers to Ref. 3 and "b" refers to values derived from the procedures discussed in this section.

25. Page 16, Table 7. An alternative format would be the following. One would modify the table by removing the "Days 403403403 ..." and "Days $459459 .$. " rows. In the column under Cycle 2, I would put (403d) and (459d) under Cycle 3. The time before irradiation and during downtime could be moved to a footnote, and the 0 burnup rows before irradiation during downtime and postirradiation have no value and should be removed.

26. Page 16, Table 8, last row. We believe the word "Total" is meant where the word "Summa" is used. The units of burnup should be "MWd/kgHM."

27. Page 17, Table 9. The word "Assemble" should be "Assembly." 
28. Page 18, Sect. 4.2, second and third paragraphs. The word "disintegration" is not the best choice here. Instead of "fuel disintegration," one should say "fuel fissioned or transmuted."

29. Page 18, Table 10. The second and third part of the table should be "Pin ID" and "height, in" as in the earlier tables.

30. Page 19, Table 11. It would be useful to list the estimated burnup for each sample in the column header with the Pin ID and height, as is done in Table 13. This would make it easier to try to assess trends as a function of burnup in the table. The same is true for Table 12.

31. Table 12. The title and "List of Tables" entry for Table 12 has formatting problems.

32. Page 21, Table 13. "Pin ID" row entries should be explained (i.e., ID plus position).

33. Page 22, second list item. The word "nainly" should be "mainly."

34. Page 22, general. This list does not mention the sensitivity of plutonium nuclides to the spectrum. Low-energy resonances in plutonium nuclides ${ }^{239} \mathrm{Pu},{ }^{240} \mathrm{Pu}$, and ${ }^{241} \mathrm{Pu}$ (especially the $0.3 \mathrm{eV}$ resonance in ${ }^{239} \mathrm{Pu}$ ) make plutonium more sensitive to the thermal spectrum than uranium nuclides. It is possible that poor plutonium predictions result from poor thermal spectrum representation (inadequate modeling of thermal in-leakage from surrounding LEU assemblies).

35. Page 22, line 4. What does "drop out of common row" mean?

36. Page 22, line 5. The phrase "of sample of 141 pin" should be changed to "those from sample pin 141."

37. Page 22, line 8 . Change to "the balance equation."

38. Page 22, line 8. Change "errors" to "error's."

39. Page 22. ${ }^{241} \mathrm{Pu}$ decay...

40. Page 23, last paragraph. SCALE SAS2H calculations are based on a very approximate 1-D assembly calculation, but according to the appendix, they are very similar to the detailed geometry model used in these analyses. This would indicate that perhaps the problem is not in the level of geometry modeling detail or that approximations in SCALE provide compensating errors.

41. Page 23. How is the plutonium content (i.e., $3 \%$ difference) related with "error of ${ }^{239} \mathrm{Pu}$ isotope"?

42. Page 23. Change to "So it is desirable to continue."

43. Page 24, References. Item 1. "Neutrronics" should be "Neutronics."

44. Page 25, Appendix. Table 14 is missing the footnotes (as used in Table 13 on page 21). 
45. Page 25, Table 14. Explain the "Pin ID" entries for the table. Table 14 should be named Table A1 (as the appendix table in Part 2 is named).

\section{Review of Part 2. Calculation Analysis of San Onofre PWR MOX Fuel Depletion Data with CONKEMO Code}

1. If the two parts of this study are to be published in a single volume, then a single page numbering sequence would be a preferred format.

2. Page 2, Introduction. The American term for "code-constant package" is cross-section data processing system.

3. Page 3, Fig. 1 caption. "Onorfe" should be "Onofre."

4. Page 4, publication error. Should be "Instrumentation Tube." Figure 2 gives the same information provided in Fig. 1 of Part 1. Again, if the two parts are to be published as one report, it is possible to remove some of the redundancy.

5. Page 4, Fig. 2 caption. "Onorfe" should be "Onofre."

6. Page 5, Table 1. The word "Mederator" should be spelled "Moderator."

7. Page 6, Table 2. The word "Shundown" should be spelled "Shutdown." The titles "Cycle 1" and "Cycle 2" should be reversed. The pin ID and height are missing.

8. Page 6. The number " 8 " should be written as "eight" (words used for numbers <10).

9. Page 6, first paragraph. It is unclear whether decay of ${ }^{241} \mathrm{Pu}$ to ${ }^{241} \mathrm{Am}$ was accounted for just during the downtime between cycle 1 and cycle 2 .

10. Page 7, Fig. 3. The word "assemble" should be "assembly."

11. Page 8, last paragraph. Change to "Ratios of calculated to experimental isotopic densities averaged over four samples."

12. Page 8. Change to "over six samples."

13. Page 8 , fourth paragraph. The word "Sities" should be changed to "Cities."

14. Page 8, fourth paragraph. More information should be provided on the Quad Cities analysis; was the fuel assembly similar, such that similar results would be expected? What differences are there?

15. Page 10, Table 3. Reference should be provided for SCALE results.

16. Page 9, in caption. It should read "Average calculated/experimental (c/e) ratios."

17. Page 9. The ${ }^{239} \mathrm{Pu}$ ratios are quite good. In Part 1 (p. 23), ${ }^{239} \mathrm{Pu}$ was supposed to be the cause of error. 
18. Page 10, Table 3. The table caption should say "calculated-measured" (not the other way around).

19. Page 11, caption for Fig. 5 and the figure legend. The word "Sities" should be "Cities." Again, the caption should read "Average calculated/experimental (c/e) ratios."

20. Page 12. Change to "a correlation."

21. Page 13, line 1 and line 4. The word "then" should be changed to "than."

22. Page 13. In regard to the statement "accumulation of ${ }^{238} \mathrm{Pu}$ being too low," this is probably, as discussed earlier, because ${ }^{242} \mathrm{Cm}$ and its alpha-decay to ${ }^{238} \mathrm{Pu}$ are not accurately modeled.

23. Page 13. Reference 3 is in Cyrillic.

24. Page 13, item 2. Change to "over four samples" and "over six samples."

25. Page 13. Change to "serve as a basis."

26. Page 14, Table A1. The title should be changed to "Ratios of calculated to measured atom densities" or something similar. 


\section{ORNL/SUB/00-85B99398V-8}

\section{INTERNAL DISTRIBUTION}

$\begin{aligned} \text { 1-5. } & \text { B. B. Bevard } \\ \text { 6. } & \text { M. D. DeHart } \\ \text { 7. } & \text { F. C. Difilippo } \\ \text { 8. } & \text { M. E. Dunn } \\ 9 . & \text { R. J. Ellis } \\ \text { 10. } & \text { J. C. Gehin } \\ \text { 11. } & \text { S. R. Greene } \\ \text { 12. } & \text { D. Hollenbach } \\ \text { 13. } & \text { D. T. Ingersoll } \\ \text { 14. } & \text { M. A. Kuliasha }\end{aligned}$

\author{
15. S. B. Ludwig \\ 16. G. E. Michaels \\ 17. B. D. Murphy \\ 18. C. V. Parks \\ 19. W. P. Poore III \\ 20-21. R. T. Primm III \\ 22. C. C. Southmayd \\ 23. R. M. Westfall \\ 24. Central Research Library \\ 25. ORNL Laboratory Records-RC
}

\section{EXTERNAL DISTRIBUTION}

26. N. Abdurrahman, College of Engineering, Department of Mechanical Engineering, University of Texas, Austin, Texas 78712

27. M. L. Adams, Department of Nuclear Engineering, Texas A\&M University, Zachry 129, 3133 TAMU, College Station, TX 77843

28. D. Alberstein, Los Alamos National Laboratory, P.O. Box 1663, MS-K551, Los Alamos, NM 87545

29. J. B. Briggs, Idaho National Environmental and Engineering Laboratory, P.O. Box 1625-3855, Idaho Falls, ID 83415-3855

30. N. Fletcher, Office of Fissile Materials Disposition, U.S. Department of Energy, 1000 Independence Avenue SW, NN-63, Washington, DC 20585

31. K. Chidester, Los Alamos National Laboratory, P.O. Box 1663, MS-E502, Los Alamos, NM 87545

32. W. Danker, U.S. Department of Energy, NN-62, 1000 Independence Avenue SW, Washington, DC 20585

33. T. Gould, Lawrence Livermore National Laboratory, P.O. Box 808, MS-L186, Livermore, CA 94551

34. L. Jardine, Lawrence Livermore National Laboratory, P.O. Box 808, MS-L166, Livermore, CA 94551

35. Dr. Alexander Kalashnikov, Institute of Physics and Power Engineering, 1 Bondarenko Square, Obninsk, Kaluga Region, Russia 249020

36. S. L. Passman, Booz-Allen \& Hamilton, 555 13th Street, NW, 480E, Washington, DC 20004

37-41. Dr. Alexander Pavlovitchev, Russian Research Center "Kurchatov Institute," Institute of Nuclear Reactors, VVER Division, VVER Physics Department, 123182, Kurchatov Square, 1, Moscow, Russia

42. K. L. Peddicord, Associate Vice Chancellor, Texas A\&M University, 120 Zachry, College Station, TX 77843-3133

43. G. Radulescu, Framatom Cogema Fuels, 1261 Town Center Drive, MS-423, Las Vegas, Nevada 89143 
44. P. T. Rhoads, Office of Fissile Materials Disposition, U.S. Department of Energy, NN-61, 1000 Independence Avenue SW, Washington, DC 20585

45. J. Thompson, Office of Fissile Materials Disposition, U.S. Department of Energy, NN-61, 1000 Independence Avenue SW, Washington, DC 20585

46. F. Trumble, Westinghouse Savannah River Company, Building 730R, Room 3402, WSRC, Aiken, SC 29808

47. R. H. Clark, Duke/Cogema/Stone \& Webster, 400 South Tryon Street, WC-32G, P.O. Box 1004, Charlotte, NC 28202

48. S. Nesbit, Duke/Cogema/Stone \& Webster, 400 South Tryon Street, WC-32G, P.O. Box 1004, Charlotte, NC 28202

49. M. S. Chatterton, Office of Nuclear Reactor Regulation, MS O10B3, U.S. Nuclear Regulatory Commission, Washington, DC 20555-0001

50. R. W. Lee, Office of Nuclear Reactor Regulation, MS O10B3, U.S. Nuclear Regulatory Commission, Washington, DC 20555-0001

51. U. Shoop, Office of Nuclear Reactor Regulation, MS O10B3, U.S. Nuclear Regulatory Commission, Washington, DC 20555-0001

52. Nagao Ogawa; Director and General Manager; Plant Engineering Department; Nuclear Power Engineering Corporation; Shuwa-Kamiyacho Building, 2F; 3-13, 4-Chome Toranomon; Minato-Ku, Tokyo 105-0001, Japan

53. Dr. Kiyonori Aratani; Surplus Weapons Plutonium Disposition Group; International Cooperation and Nuclear Material Control Division; Japan Nuclear Cycle Development Institute; 4-49 Muramatsu, Tokai-mura, Naka-gun, Ibaraki-ken, Japan

54. Boris E. Volkov, Head of Division, EDO Gidropress, 21 Ordzhonikidze Street, Podolsk, Moscow District, Russia 142103

55. Dr. Alexandre Ermolaev, Balakovo Nuclear Power Plant, Saratov Region, Balakovo-26, Russia 413866 